\title{
Convective Rainfall Systems in the La Plata Basin
}

\author{
Augusto J. Pereira Filho', Richard E. Carbone2, John D. Tuttle ${ }^{2}$ \\ ${ }^{1}$ University of São Paulo, Institute of Astronomy, Geophysics and Atmospheric Sciences, Department of \\ Atmospheric Sciences, São Paulo, Brazil \\ ${ }^{2}$ National Center for Atmospheric Research, Colorado, USA \\ Email: augusto.pereira@iag.usp.br, carbone@ucar.edu, tuttle@ucar.edu
}

Received 10 September 2014; revised 12 October 2014; accepted 25 October 2014

Copyright (C) 2014 by authors and Scientific Research Publishing Inc.

This work is licensed under the Creative Commons Attribution International License (CC BY). http://creativecommons.org/licenses/by/4.0/

(c) (i) Open Access

\section{Abstract}

Hourly rainfall estimates from integrated satellite data are used to build a dynamically based climatology of convectively generated rainfall across the La Plata Basin in South America and adjacent oceans. Herein, the focus of this manuscript is on $20 \mathrm{~S}$ to 35S, including the Andes cordillera. Emphasis is placed on rainfall resulting from organized convective regimes which are known to produce the majority of seasonal rainfall in Southern South America and other continents. The statistical characteristics of individual events are quantified and examined with respect to regional atmospheric conditions. Among the factors considered are steering winds and wind shear, convective available potential energy (CAPE), localized sensible and latent heat sources over mountains and wetlands (Chaco), and the occurrence of baroclinic waves such as mid-latitude jet stream transient disturbances. Forcing and convective triggering mechanisms are inferred from the diagnosis of systematic patterns as evidenced in the continental diurnal cycle and longer periods of natural variability. The diurnal cycle of rainfall is especially informative with respect to the frequency and phase of rainfall associated with long-lived propagating rainfall "episodes". Similar to findings in tropical northern Africa and tropical northern Australia, there is a strong presence of organized convection, which can propagate zonally hundreds to thousands of $\mathrm{km}$ as a coherent sequence of mesoscale convective systems. Convective triggering is often associated with elevated terrain, the Andes, and the La Plata basin region, which is especially rich in moist static energy. The passage of baroclinic waves over the Andes is consistent with eastward propagating clusters of convection, within which westward-propagating systems also reside. These organized convective systems over the La Plata Basin are analyzed with hourly rainfall estimates with CMOPRH method. Rainfall estimates at 8-km spatial resolution were obtained between December 2002 and June 2008. Very few data are missing so it is one of the most complete, longest and highest resolution data sets available to date that allows a comprehensive description of spatial and temporal distribution of convection from its hourly to interannual variability over the region. In this work, diurnal, intra and inter seasonal and interannual cycles are obtained and examined in the light of 
episodes of organized convection. Daily, monthly and yearly spatial patterns of rainfall accumulation over the La Plata Basin region vary both inter- and intra-seasonally and are forced by underlying dynamic and thermodynamics mechanisms. Time-longitude diagrams of CMORPH hourly rainfall are used to describe the genesis, structure, longevity, phase speed and inferences of the underlying dynamics and thermodynamics of episodes of organized convection. The episodes of organized convection are analyzed in terms of their duration, span, phase speed, starting and ending time, starting and ending longitude, month and year through frequency distribution analysis. Most episodes of organized convection move eastward across the La Plata Basin with variable phase speeds. Basic descriptive statistics indicate that the La Plata eastward propagating average phase speed is $13.0 \mathrm{~m} \cdot \mathrm{s}^{-1}$.

\section{Keywords}

\section{Satellite-Derived Rainfall, Organized Convection, La Plata Basin, Diurnal Cycle}

\section{Introduction}

This South America has two major precipitating regions that shaped both the Amazon and the La Plata Basins as readily seen in their topography features (Figure 1 ). Continental and basin scale water balances are economically relevant to human activities, though more importantly, they determine the complexity of eco systems such as those found in the Amazon and Chaco regions. South America has one of the largest drainage systems with about $12 \%$ of all fresh water on the planet. A major contributor to the hydrological cycle in the La Plata basin is the frequent occurrence of mesoscale convective systems (MCSs). [1] compared these over North and South America and concluded the latter region produces stronger, larger and longer lasting events. These systems tend to form during evening hours in spring and summer yielding larger amounts of water [2]. The transport of heat and moisture by the South America low level jet-SALLJ [3] assists in the triggering of events close to the Andes Mountain Range. This occurs most frequently near 25S; southward with variable easterly trajectories in fall and spring; and northward in summer [1]. Precipitation climatology of such systems and others that contribute to the water cycle over the La Plata Basin are important and difficult to obtain from point measurements alone to establish major event regimes, diurnal cycle, seasonality, and variability out to inter-annual periods. This paper focuses on precipitation climatology over the La Plata region from a 5-year period of record. Event-based rainfall statistics include spatial and temporal coherence, frequency and intensity of events, preferred locations and diurnal phase of rainfall triggering; continental and coastal ocean patterns of diurnal, seasonal, interannual variability. The underlying dynamical mechanisms and diurnal variability are inferred and discussed based on spatially resolved and hourly cumulative rainfall estimates. This manuscript presents a brief description of the CMORPH method in Section 2 [4]. Interannual, interseasonal and diurnal spatial distribution, frequency and variability of rainfall systems are analyzed for a 5-year period of record in Section 3. Event characteristics are illustrated in Section 4, diurnal patterns and inferred causes thereof are given in Section 5 . A brief summary of major results and conclusions is given in Section 6.

\section{Precipitation Amount and Frequency Estimation}

CMORPH (“CPC Morphing technique”; [4]) provides high spatial ( 8 $\mathrm{km}$ at the equator) and temporal (half-hourly) analyses of precipitation globally from $60^{\circ} \mathrm{N}$ to $60^{\circ} \mathrm{S}$. The method blends together precipitation estimates from passive microwave (PMW) instruments (SSMI, AMSR-E, AMSU, TMI) that are generated from published algorithms. However, since these instruments are from low earth orbit platforms, sampling frequency is a major shortcoming. CMORPH alleviates sampling limitations by using geosynchronous infrared (IR) data as a mechanism to interpolate and "morph" the PMW-derived precipitation estimates yielding spatially and temporally complete precipitation fields every 1/2 hour. CMORPH differs from other combined IR/PMW methods (e.g., TMPA; [5]; PERSIANN; [6]) in that it does not use rainfall estimates generated from IR data. Rather, it uses IR to determine the motion of raining systems and applies that motion field to raining systems that have been determined from passive microwave (PMW) data. The hypothesis is that the use of IR data to transport and 


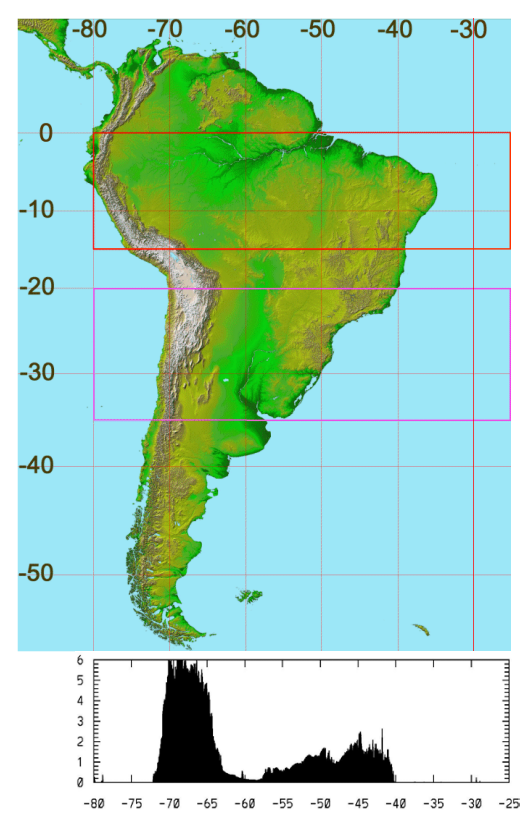

Figure 1. USGS topographic (A) of South America between $10^{\circ}$ and $-60^{\circ}$ latitudes and between $-25^{\circ}$ to $-90^{\circ}$ longitudes. Geographic contours, latitudes and longitudes are indicated in the maps. The La Plata rectangle is between $-20^{\circ}$ and $-35^{\circ}$ latitudes, and between $-25^{\circ}$ and $-80^{\circ}$ longitudes.

interpolate precipitation systems (that have been identified and quantified by PMW data) results in more accurate estimates than those from IR data alone. This notion is borne out by several validation studies (e.g., [7]). The details of the process are provided by [4].

\subsection{CMORPH Daily, Monthly and Yearly Accumulation}

Figure 1 shows a topographic map of South America and the area where daily, monthly, seasonal and annual rainfall accumulation were estimated to analyze interannual, intraseasonal and daily cycle of convection over the La Plata Basin from 2003 to 2007 . The rectangle determined by latitudes $20^{\circ} \mathrm{S}$ to $35^{\circ} \mathrm{S}$ and by longitudes $25^{\circ} \mathrm{W}$ to $80^{\circ} \mathrm{W}$ is the area where CMORPH hourly rainfall accumulation were taken. [8] compared gauge-measured and CMOPRH-derived rainfall accumulation over most of South America for 2003 and 2004. They indicated better correlation for longer accumulation time intervals with $\rho^{2}=0.72,0.62$ and 0.38 for yearly, monthly and daily rainfall accumulation. Further yearly one-hour rainfall climatology analyses over South America are shown in [8] where the focus is the diurnal cycle of convection over the Amazon and adjacent tropics. They described the annual rainfall in seven spatial patterns: 1) an area of high rainfall accumulations over the Amazon Basin; 2) a secondary area of high rainfall accumulation over the La Plata basin; 3) a broad area of fairly high precipitation over the South Atlantic Ocean; 4) a very low rainfall area induced by the South Atlantic high pressure system; 5) an area of low rainfall associated with the South Pacific high pressure system; 6) an rainfall stripe along the coast of Brazil due to warn rain processes; and 7) High rainfall down slope in the Amazonian. They found that rainfall patterns have greater interannual variability in amplitude than phase and are modulated by stationary and transient climate features [9].

\subsection{Time-Longitude Rainfall Analysis}

Hovmöller time-longitude analyses used by [10] were utilized to identify episodes of organized convection in the La Plata Basin. All systems 100-km or longer were analyzed to estimate their span, phase speed, duration, starting and ending longitudes. Statistics were obtained. Some episodes of organized rainfall are used to illustrate typical cases of short to long duration events as well as their underlying dynamics and thermodynamics and how much they contribute to the estimated total rainfall accumulation in the region. Individual and compo- 
site synoptic analyses of winds, specific humidity and temperature were obtained with NCEP analysis software. Wind shear and system steering level were also included in the analyses of dynamic features as well as respective Hovmöller diagrams. The annual and seasonal diurnal cycles of convection were obtained with averaged Hovmöller diagrams for a 48-hour period to illustrate stationary and propagating rainfall systems in the La Plata region.

\section{Seasonal and Interannual Variability}

Inter-annual and intraseasonal monthly precipitation estimation with CMORPH between 2003 and 2004 is shown in Figure 2. The monthly rainfall fields shown include two major moisture convergence zones. One is the Inter Tropical Convergence Zone (ITCZ) that produces the ascending branch of the Hadley circulation over the Amazon Basin. As suggested by the displacement of this major precipitation region, it migrates from North to South over the Amazon Basin from September to March. The second one located between the extra-tropics and mid-latitudes of South America is linked to baroclinic waves that tend to be stationary in early summer and result in the South Atlantic Convergence Zone. Two other precipitation features are of note. One is a vast region of low rainfall accumulation associated to the descending branch of the Hadley Circulation over Northeast Brazil.

This high-pressure system is a permanent feature across the South Atlantic Ocean, extending eastward to South Africa (not shown). This large divergence area transports moisture equator ward and westward by low-level winds. Zonal winds transport most of the moisture in the Amazon Basin. Secondly there is a region of enhanced precipitation caused by seasonal organized convection centered in the Chaco region within the La Plata Basin. The overall climatology of these transient systems is well established in the literature [11]. Figure 2 indicates that this secondary rainfall maximum is apparent in early fall and spring. The dynamical and thermo-dynamical features of this secondary maximum in South America are the main object of this manuscript. Similar rainfall features have been observed and analyzed in North America [10], Australia [12] and Africa [13] and were found to be associated with elevated terrain, differential heating, while propagating great distances downstream from the areas where they are formed. It will be seen later that the La Plata organized systems tend to resemble others elsewhere in most cases but the longer duration ones are caused by phase locking between the entrance region of upper level jets (ascendance) and the low level jet that injects high moisture content from the Amazon Basin to fuel organized extra tropical convection [3].

Figure 3 shows the average hourly rainfall accumulation field for South America in 2003. The diurnal cycle over the Amazon and over the La Plata Basins is the dominant rainfall regions that propagate westward and eastward, respectively. The one over the Amazon starts late in afternoon and progress to the next day while the one over the La Plata starts early in the day.

The relative rainfall accumulation in both regions are comparable but the one in the La Plata is much less frequent being more apparent in early fall and spring. In spite of many other diurnal events, these events propagate systematically, spreading rainfall in space and time through Southern South America. Such propagation renders the organized convection clearer. Other important imbedded features are ordinary convective systems over the Chaco region, but these also fail to propagate under the less favorable dynamic conditions associated with reduced vertical wind shear.

The frequency of hourly rainfall accumulation between September and November in 2003 is seen in Figure 4, the most active season of organized convection in the La Plata Basin in a year of more frequent organized convection. It is more evident in the frequency fields that events over the La Plata basin are less frequent than events over the Amazon. However, the average rainfall rate is higher in the La Plata region. Thus, this potentially more baroclinic environment associated with high moist static energy and wind shear seem them both to play an important role while over the Amazon region equatorial waves are less effective in that sense.

Figure 5 presents the frequency distributions of duration (h), phase speed $\left(\mathrm{m} \cdot \mathrm{s}^{-1}\right)$, and span (km) for all episodes of organized convection in the La Plata Basin between December 2002 and June 2008. There is a greater frequency of smaller episodes of organized convection. The average phase speed is $13.0 \mathrm{~m} \cdot \mathrm{s}^{-1}$ for eastward moving episodes. Phase speeds of longer spans can be either small or large. Longer (shorter) spans episodes can propagate very fast (very slow) depending on the underlying dynamic and thermodynamic conditions. The spectrum of phase speeds tend to be narrower (broader) for shorter (longer) durations and spans and, there are episodes of higher (lower) phase speed for longer (shorter) spans and durations. 

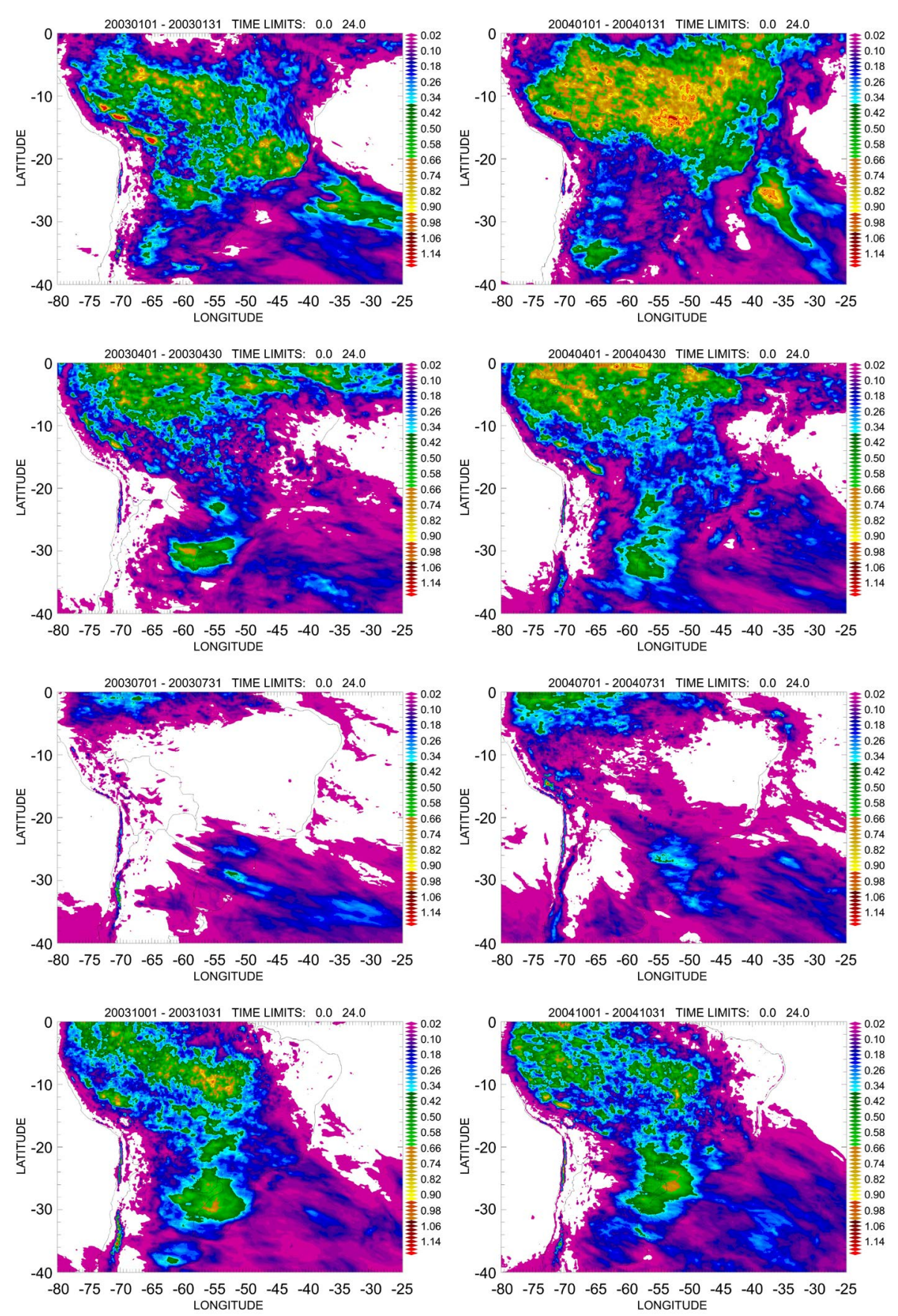

Figure 2. Monthly one-hour rainfall rate average ( $\mathrm{mm} / \mathrm{hr} / \mathrm{month}$ ) over South America for 2003 to 2004. Longitudes, latitudes, geographic contours, color scale (mm/hr/year) are indicated.

Phase speeds (not shown) have much greater dependence on the starting longitude than on the starting time. The maximum is located in the Andes Cordillera and the minimum over the South Atlantic Ocean. Systems that start between $-40^{\circ}$ to $-50^{\circ} \mathrm{W}$ longitudes in the afternoon and evening also have faster phase speeds. The high frequency of front genesis [14] and so intense circulation agrees with the present estimate of episodes of organized convection. Episodes have higher frequency between longitudes $-70^{\circ}$ to $60^{\circ} \mathrm{W}$ in the afternoon and evening close to the Andes Cordillera. A maximum at $-65^{\circ}$ longitude late evening is remarkable (Figure 6).

Spans are longer when systems start between $-70^{\circ}$ to $-60^{\circ} \mathrm{W}$. The spans tend to be shorter in the upstream direction of propagation given contour conditions at East (Atlantic Ocean) and West (Andes Mountains) that 

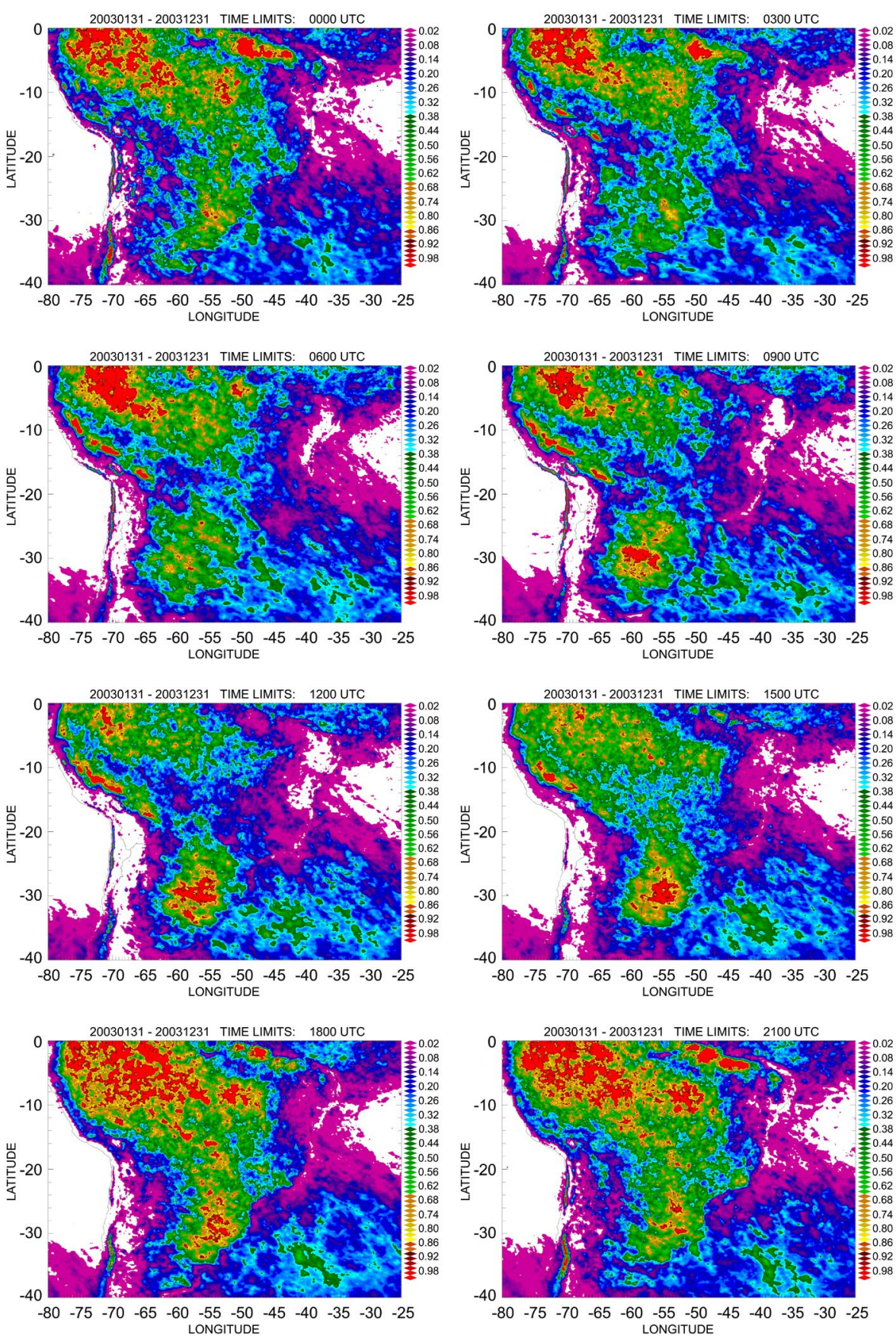

Figure 3. Average hourly rainfall accumulation field for South America in 2003 at 0000 UTC, 0300 UTC, 0600 UTC, 0900 UTC, 1200 UTC, 1500 UTC, 1800 UTC and 2100 UTC. Longitudes, latitudes, geographic contours, color scale $(\mathrm{mm} / \mathrm{hr})$ are indicated.

restrains the organized convection by lower friction and higher static stability, respectively. The frequency distribution of episodes at La Plata Basin episodes (Figure 6) stating longitudes are remarkably higher collocated to Andes Cordillera (18\%) and between longitudes $-50^{\circ}$ to $-30^{\circ} \mathrm{W}$ ( $>10$ average) over South Atlantic Ocean.

Figure 7 shows the frequency distribution of starting times of episodes of organized convection in the La Plata Basins. Frequency distribution of starting times in the La Plata Basin is complex, through the three main peaks at 0100 UTC (6.0\%), 0900 UTC (6.5\%) and 1900 UTC (5.6\%) that coincide with the ones in the Amazon Basin (not shown). Two secondary peaks and the minimum are at 1300 UTC (3.6\%), 1500 UTC (4.9\%) and 

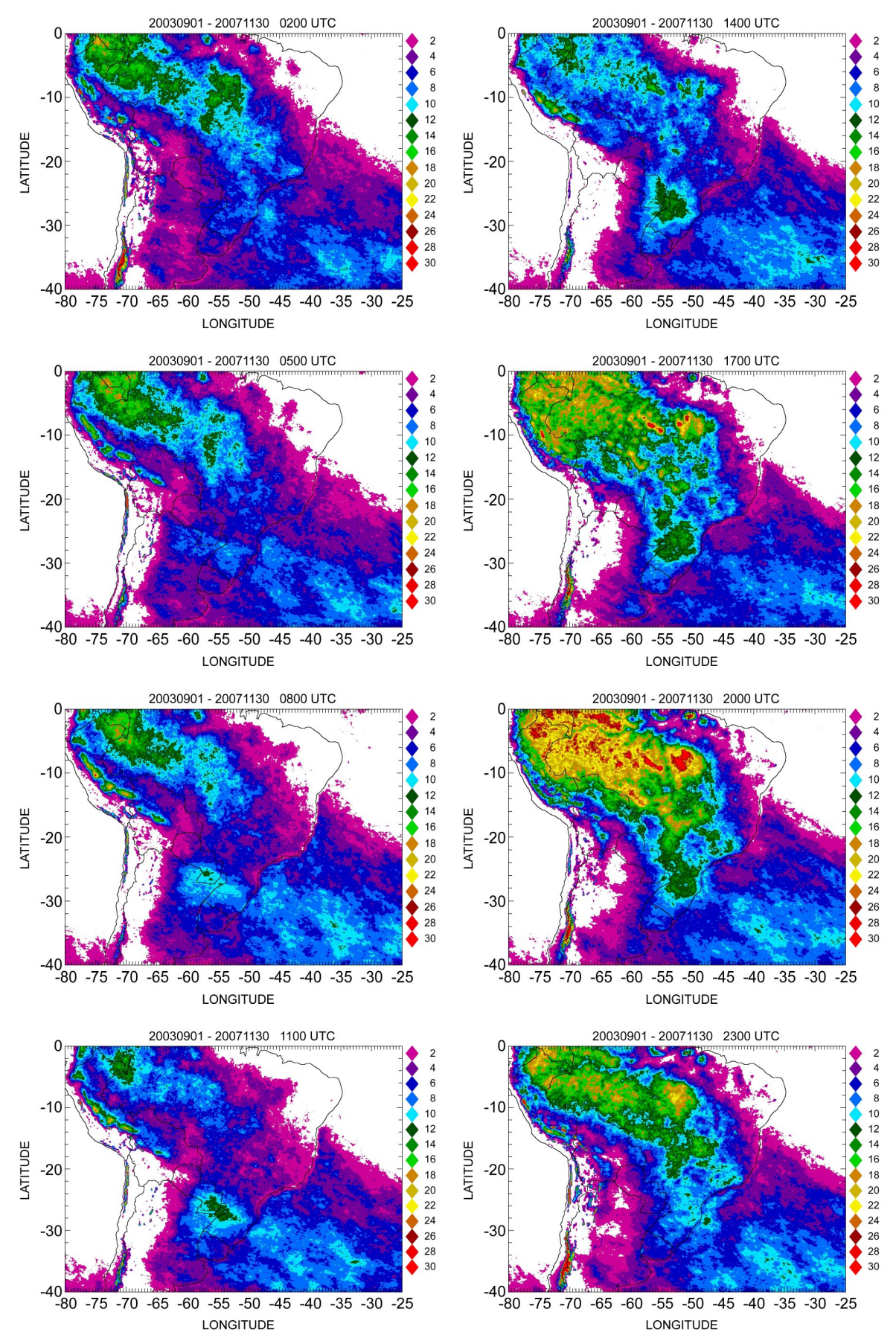

Figure 4. Frequency of hourly rainfall accumulation between September and November in 2003 at 0200 UTC, 0500 UTC, 0800 UTC, 1100 UTC, 1400 UTC, 1700 UTC, 2000 UTC and 2300 UTC. Longitudes, latitudes, geographic contours, color scale (\%) are indicated.

0000 UTC. Episodes of organized convection in the La Plata are modulated by the diurnal cycle of convection, as in the Amazon basin, and modified by the other dynamic and thermodynamic features such as transient baroclinic waves (fronts), topographic induced convection (Andes Cordillera) and frontogenesis (South Atlantic Ocean) that tend to interact with the diurnal cycle in any constructive or destructive phase between them. The most intense and lasting ones are associated to topographic induced convection fed by a low level moisture jet coming from the Amazon Basin [15]. 

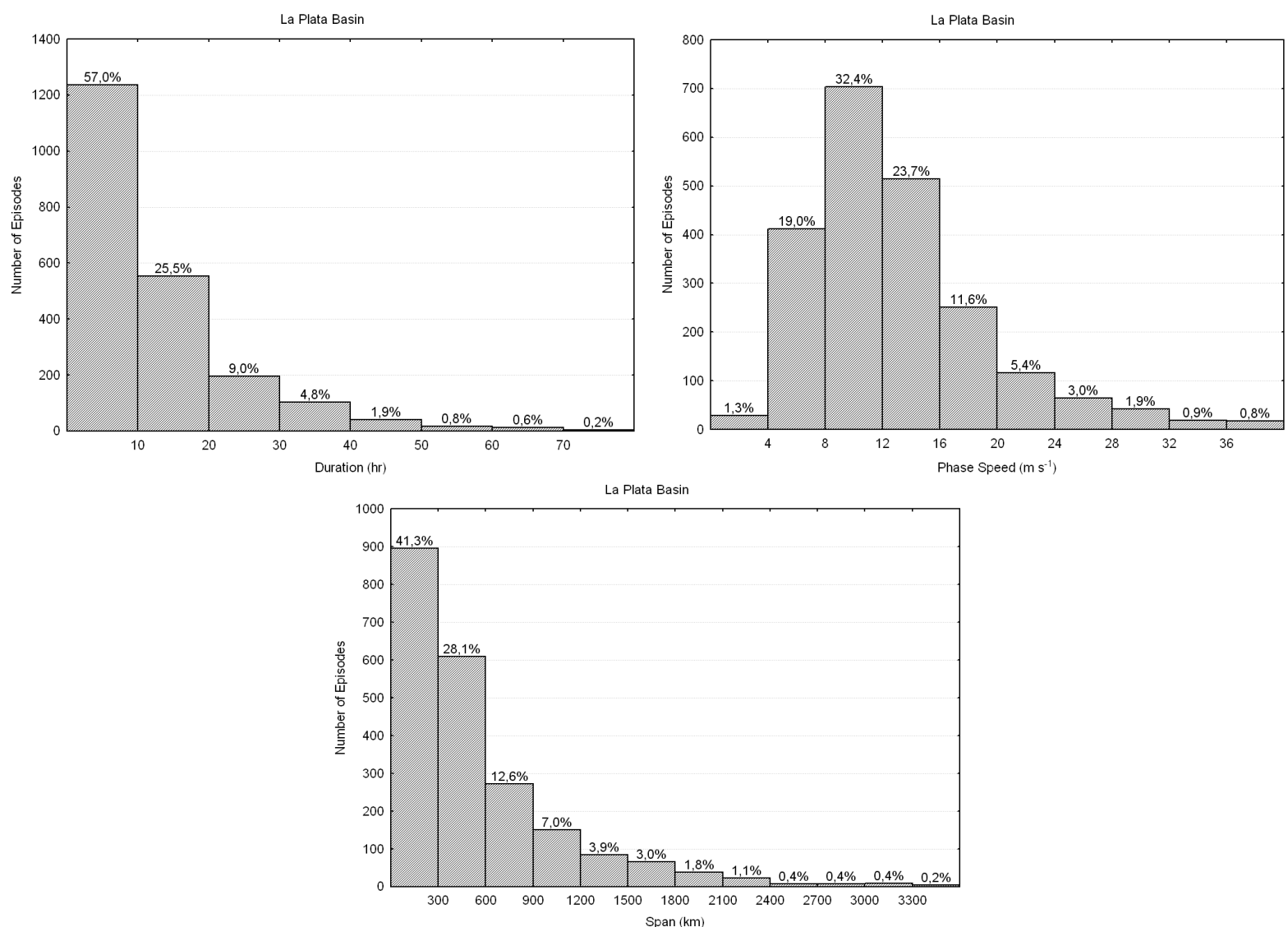

Figure 5. Frequency distribution of duration (top-left), phase speed (top-right) and span (bottom) of Eastward episodes of organized convection in the La Plata Basin between December 2002 and June 2008.
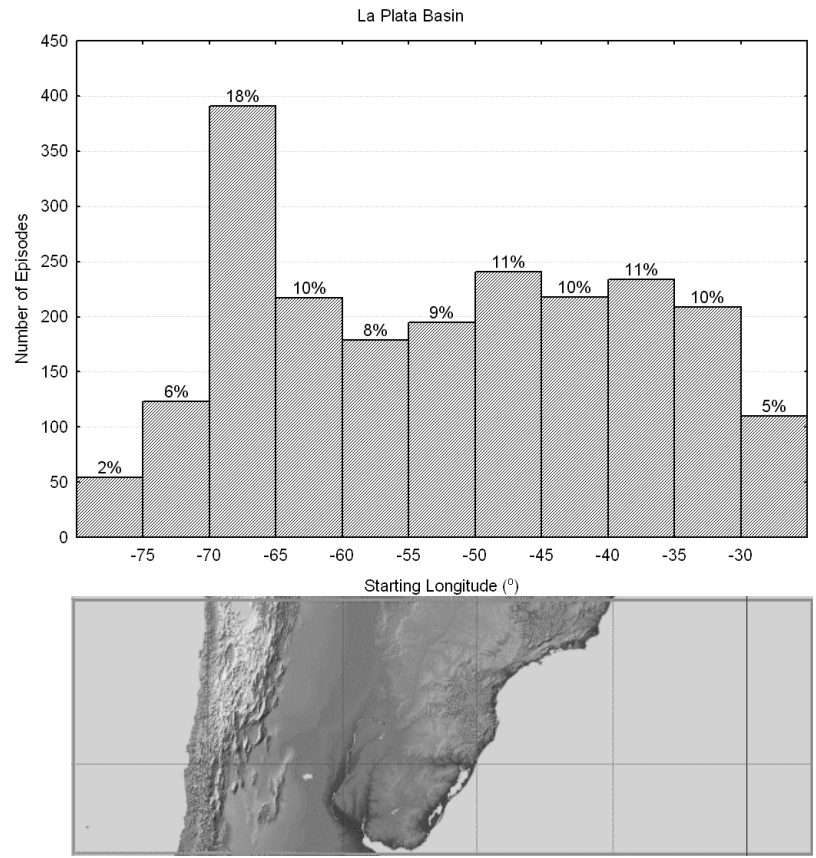

Figure 6. Frequency distribution of starting longitudes $\left(^{\circ}\right)$ of organized convection in the La Plata Basin for the months of October, November and December of 2002 to 2007. 


\section{Diurnal Cycle}

Figure 8 shows the Hovmöller time-longitude diagram for one-hour rainfall accumulation average in a 48-hour period computed with CMOPRH rainfall estimation in the La Plata domain between 2002 and 2008. The main rainfall pattern in the Hovmöller diagram is the diurnal cycle of convection starting near the Andes Cordillera $\left(-67^{\circ} \mathrm{W}\right)$ around $0000 \mathrm{UTC}$ and propagates eastward in about one day to $-46^{\circ} \mathrm{W}$. In general, it rains less at the Cordillera, but as the organized convection propagates eastward, it increases towards the Chaco low elevation region when moist static energy is higher in late afternoon. As organized convection propagates away from the Chaco, topography increases eastward; air temperate and moisture content decrease and so rainfall, in spite of induced vertical motion by the topography. A quasi-stationary pattern is observed between seashore and the Atlantic Ocean associated with the inertial circulation along the coast, especially during summer.

Figure 9 is similar to Figure 8 except for the percentage of time with rainfall during winter, spring, summer

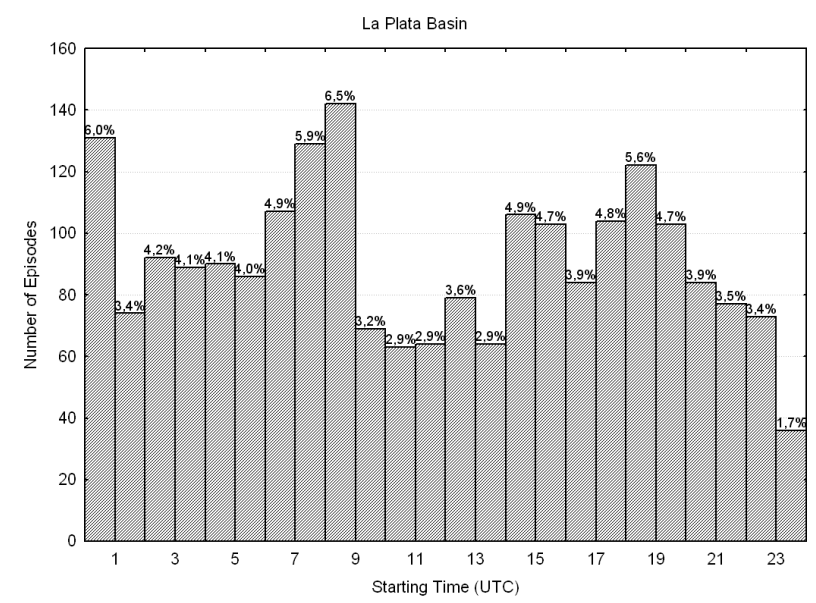

Figure 7. Frequency distribution of stating time (UTC) of organized convection in the La Plata Basins between October and December of 2002 to 2008.

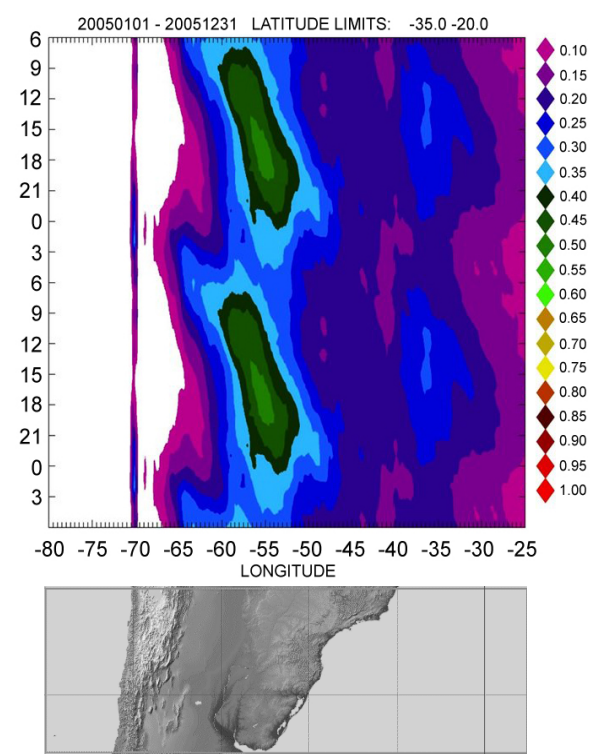

Figure 8. Hovmöller time-longitude diagram for one-hour rainfall accumulation average in a 48-hr period computed with CMOPRH rainfall estimation in the La Plata domain for between 2002 and 2008. 


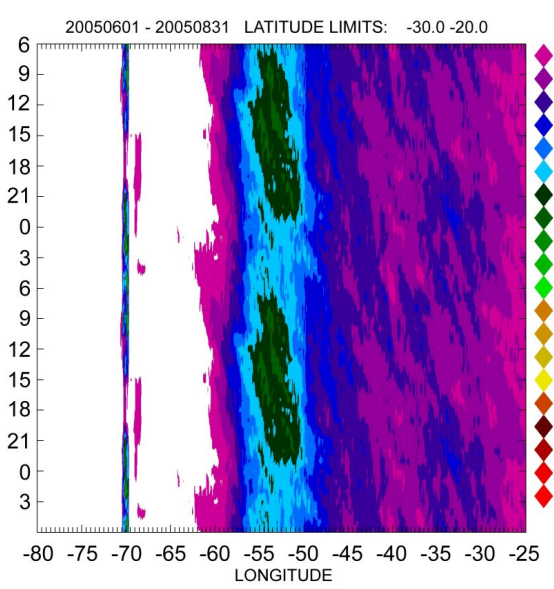

(a)

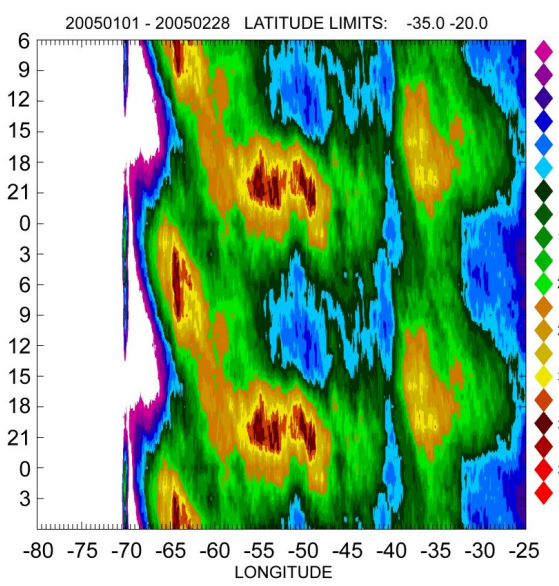

(c)

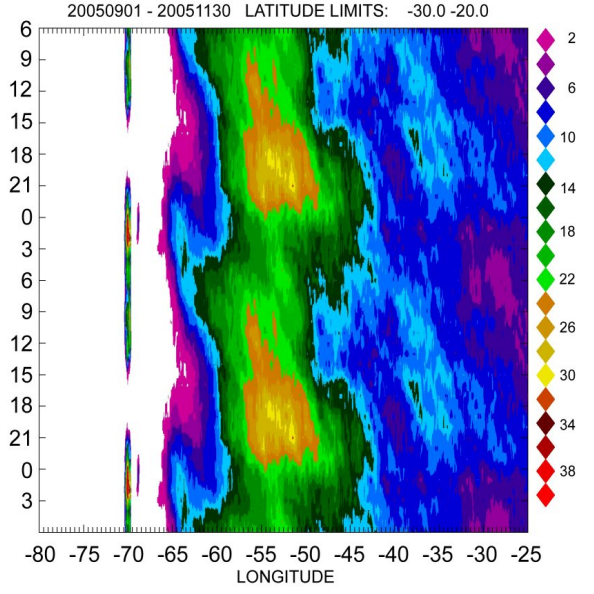

(b)

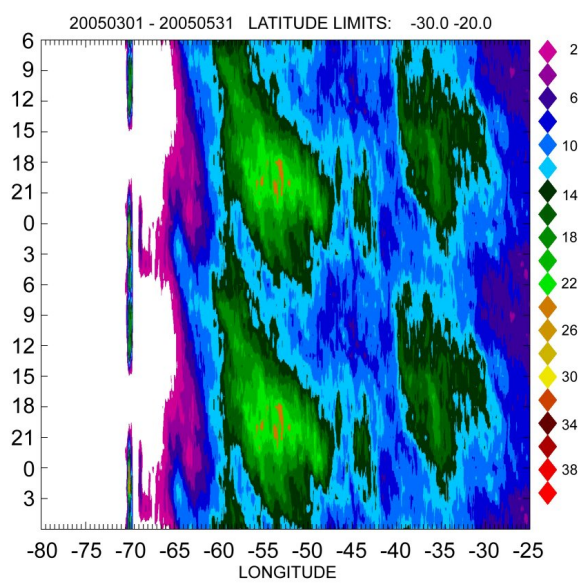

(d)

Figure 9. Similar to Figure 8 for the percentage of time with rainfall during winter (a), spring (b), summer (c) and fall (d).

and fall (a, b, c, d), respectively. A rainfall frequency pattern is almost stationary in winter centered in the Chaco region. In spring, the pattern propagates from Andes Cordillera eastward while in summer, rainfall frequency increases and stationary patterns are apparent and caused by stronger diabatic forcing. A similar pattern is observed in fall but with lower frequencies. Organized convection occurs preferably in spring and fall triggered at the Andes late in the evening. They tend to intensify as they move towards a richer moist static in phase with the diurnal cycle of diabatic.

\section{Organized Convection Characterization}

A few episodes of organized convection are presented to illustrate common instances of such systems together with their underlying dynamic and thermodynamics. Figure 10 shows a sequence of five episodes of organized convection between 23 and 29 November 2003. The Hovmöller diagram of one-hour rainfall accumulation average is shown in Figure 10(a). They started near the Andes at $-67^{\circ} \mathrm{W}$ and ended at $-45^{\circ} \mathrm{W}$. As they propagated eastward, the rainfall accumulation increased up to the Chaco region and after decreased.

The Hovmöller diagram of 200-hPa zonal wind anomalies in Figure 10(b) shows a positive anomaly evolving in magnitude and extension starting from the Andes and propagating eastward its phase displacement coincides with the phase of the precipitating systems. The average 200-hPa wind field during the episodes (Figure 10(c)) indicated an upper level jet with its equatorial entrance (ascending motion) over the Chaco region. Concomitantly, the average 925-hPa specific humidity field (Figure 10(d)) varied between $14 \mathrm{~g} \cdot \mathrm{kg}^{-1}$ to $22 \mathrm{~g} \cdot \mathrm{kg}^{-1}$ over 


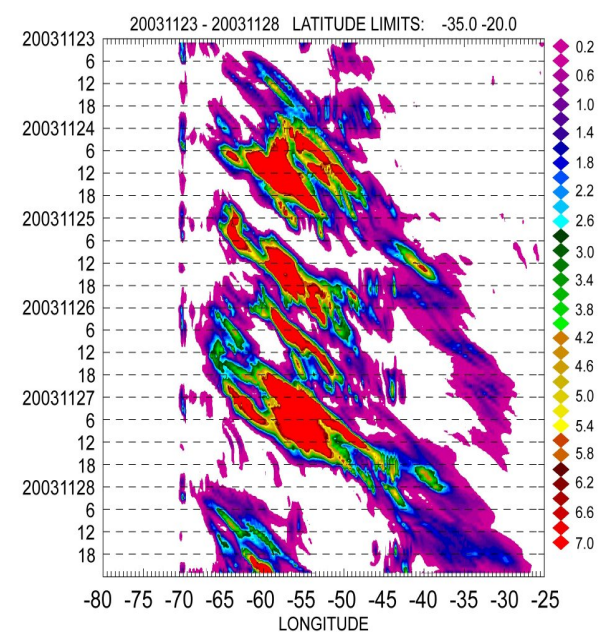

(a)

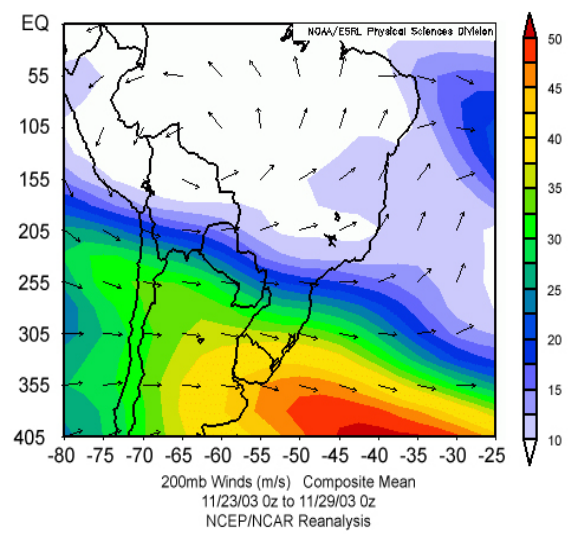

(c)

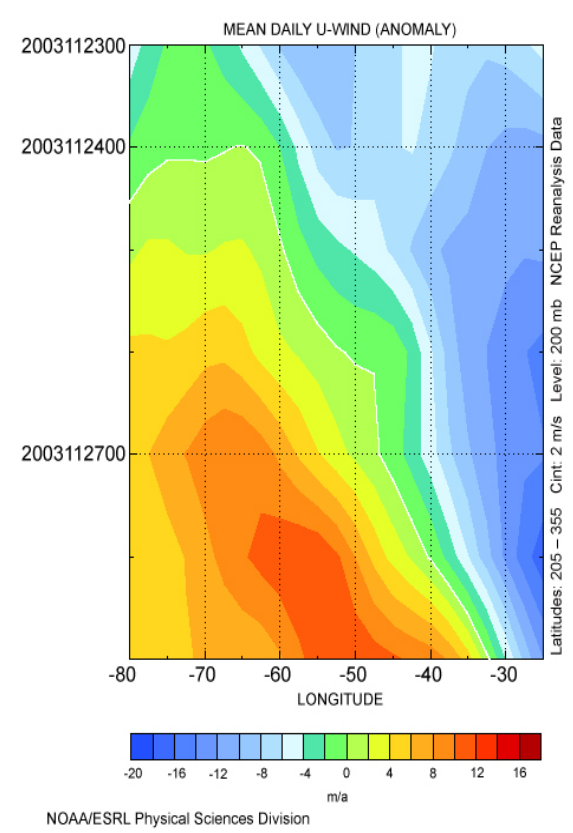

(b)

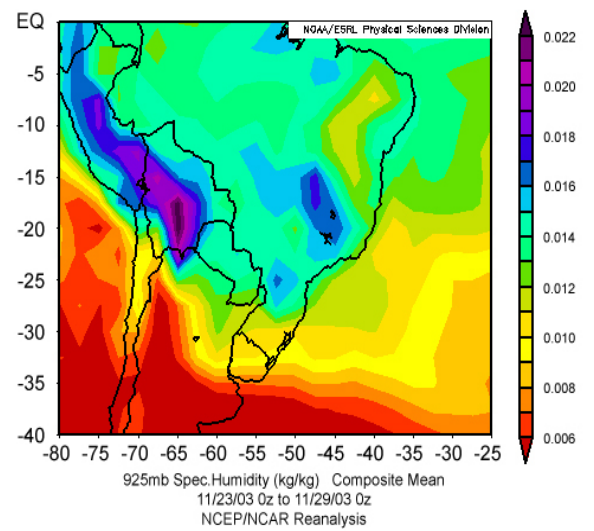

(d)

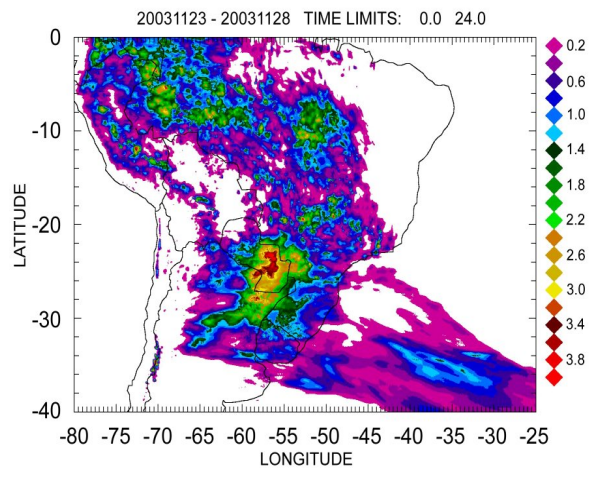

(e)

Figure 10. Episodes of organized convection between 23 and 29 November 2003. It shows Hovmöller diagrams of one-hour rainfall accumulation average (a) and 200-hPa zonal wind anomalies (b); the average 200-hPa wind field (c), average 925-hPa specific humidity (d) and the resulting rainfall accumulation (e). Longitudes, latitudes, geographic contours, color scale are indicated. 
the upper La Plata basin resulting from intense moisture advection by a low level jet (not shown). The spatial distribution of the rainfall accumulation is shown in Figure 10(e).

These key ingredients of the episodes were vertical shear and moisture advection triggered five propagating organized convective systems, and more importantly, the triggering region was over the Andes and late in the evening. This result is similar to the one found by Carbone at al. (2002) in North America downwind from theRocky Mountains. As this long baroclinic wave moved through, it produced cyclogenesis and precipitation over the Atlantic Ocean (Figure 10(c)).

Shorter-lived episodes of organized convection occurred between 02 and 12 Feb 2004 (Figure 11). The Hovmöller diagram of rainfall (Figure 11(a)) indicates three systems between 02 and 05 Feb 2004 starting about 0000 UTC near the Andes. Stationary convection is seen in the afternoon hours of 05 Feb 2004 associated to the diurnal diabatic heating. Organize systems are concentrate towards the east near and over the Atlantic Ocean between 06 and 12 Feb 2004. The corresponding Hovmöller diagram of 200-hPa zonal wind (Figure 11(b)) shows westerlies associated to weak jet (Figure 11(c)). On the other hand, moisture advection (not shown) was stronger with higher specific humidity further south and near the Andes but lower over the Chaco region resulting from pool of colder air behind a surface front (Figure 11(d)). The estimated total rainfall accumulation was less than the previous episodes (Figure 11(e)). In this instance, the dynamics was somehow weaker under drier boundary layer in the La Plata Basin.

Figure 12 shows another two episodes of organized convection one long and another short with higher rainfall accumulation over the La Plata Basin between 11 and 19 Feb 2004. Hovmöller diagrams of rainfall accumulation (Figure 12(a)) and 200-hPa meridional winds (Figure 12(b)) indicate that the longer system was associated with an upper level wave (Figure 12(c)). The $925 \mathrm{hPa}$ specific humidity field (Figure 12(d)) indicates that the longer last system started about 1200 UTC near the Andes associated to moving trough (Figure 12(b)). This system did not yield as much precipitation (Figure 12(d)) as the first episode shown in Figure 10 under similar lower level moist conditions with less favorable position and timing of the associated upper level jet (Figure 12(c)).

An instance of organized rainfall under an intense upper level jet and dry boundary layer conditions between 01 and 12 Aug 2004 is shown in Figure 13. The Hovmöller diagrams of rainfall accumulation (Figure 13(a)) and 200-hPa zonal wind (Figure 13(b)) show convection starting before crossing the Andes at $-80^{\circ} \mathrm{W}$ and ending near $-70^{\circ} \mathrm{W}$ associated to the upper level jet (Figure 13(c)) which propagates eastward and triggers convection over the Chaco region on 06 Aug 2004. It is indeed the extension of the one before the Andes but with not favorable moist conditions given the intrusion of colder and dries air from Southern Argentina (Figure 13(d)). The average rainfall accumulation is small and more significant over the Atlantic Ocean as seen in Figure 13(e).

The last example of organized convection starting near the Chaco region associated with a deep upper level trough between 02 and 07 Oct 2004 (Figure 14) resulting three bands of wide spread precipitation as seen in Figure 14(a). The wave pattern is seen in the 200-hPa meridional wind field of Figure 14(b). The mean 200 hPa wind field during the episode (Figure 14(c)) indicates an entrance region of an intense jet over the Atlantic Ocean and another further Southwest crossing the Andes. Even though an intense low-level jet is present at 850-hPa (Figure 14(d)) injecting moisture and triggering convection at 0000 UTC of 03 to 06 Oct 2004 (Figure 14(a)), they do not propagate in the absence of upper level dynamic support. Figure 14(e) shows the average rainfall accumulation during the episode which was associated with the cold front.

\section{Long to Short Lived Organized Convection}

The 10 longest and 10 shortest span systems starting at the Andes late in the evening were identified from the Hovmöller statistics to composite mean fields of $850-\mathrm{hPa}$ and 200-hPa winds, 850 -hPa temperature and specific humidity. The fields for long and short span composites are shown in Figure 15 and Figure 16, respectively. The most interesting difference in both situations is the position of the upper level jet. The longest systems are in phase with the diurnal heating, low level moisture advection and the equatorial entrance of the upper level jet. The shortest, on the other hand, the upper level jet is a quarter of wave out of phase with the diurnal cycle. Therefore, vertical shear is an important feature to the longest system that also produces most of the observed precipitation.

Most episodes of organized convection with propagation occurred in spring. Composites of vertical cross sections of zonal and meridional winds, specific humidity, 200-hPa and 850-hPa winds and 850-hPa specific 


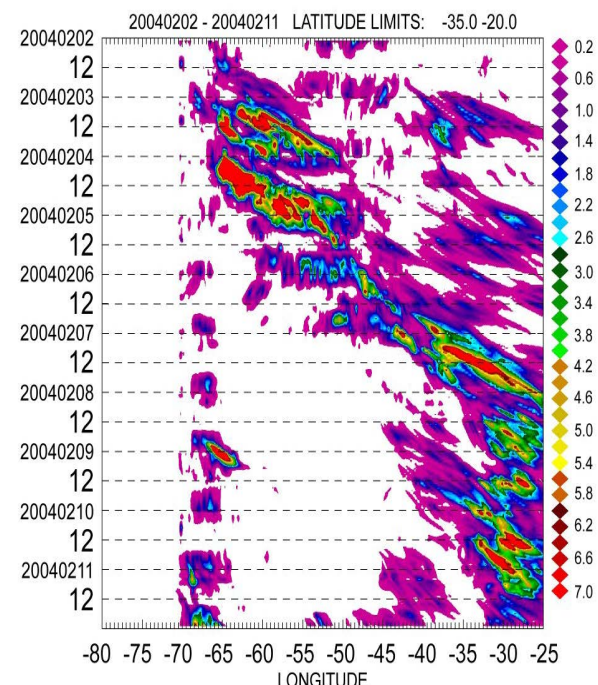

(a)

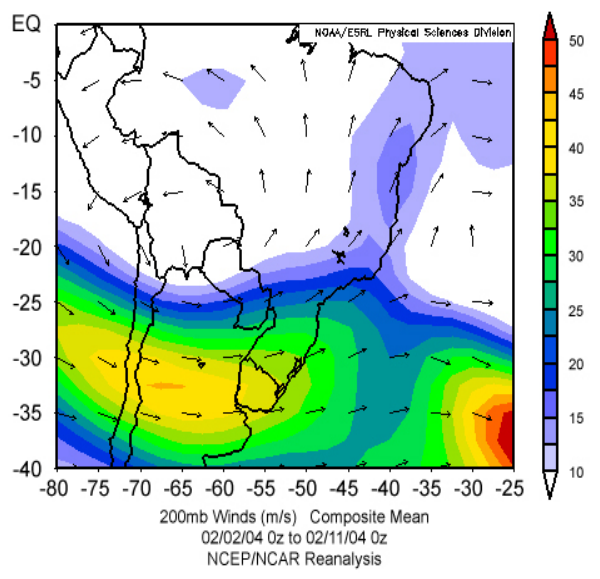

(c)

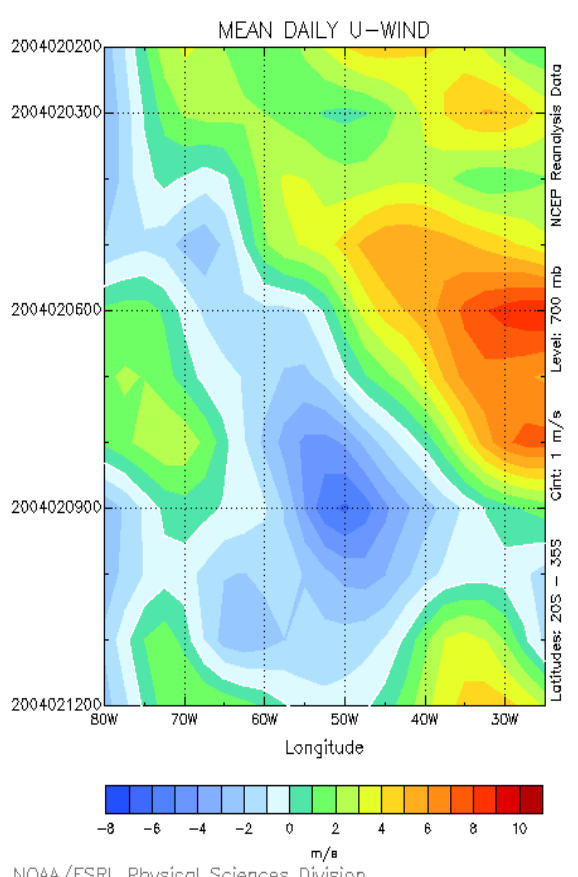

(b)

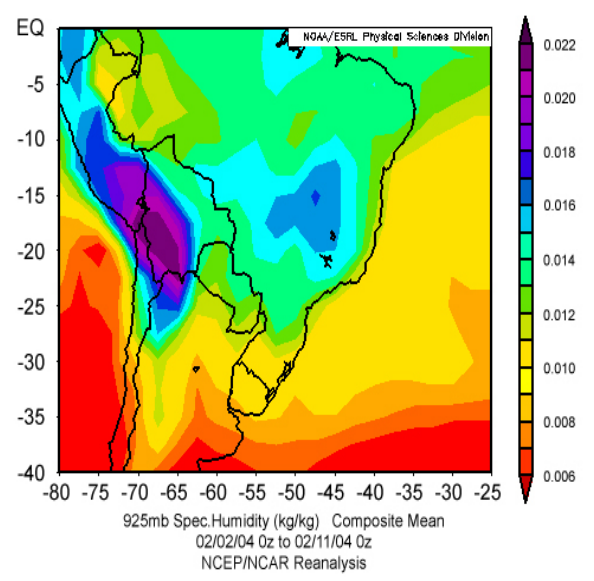

(d)

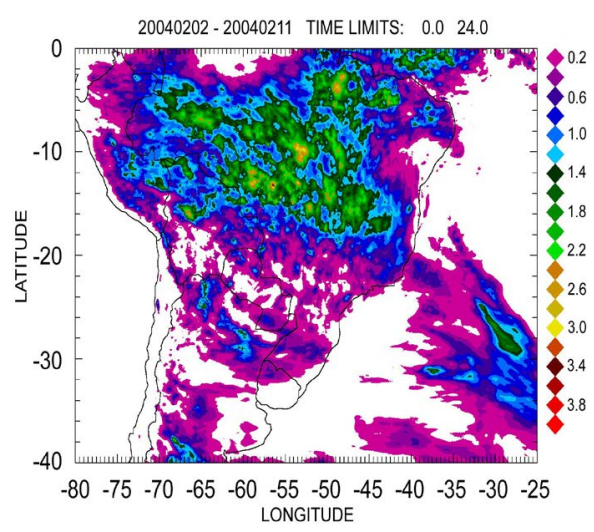

(e)

Figure 11. Similar to Figure 10 for episodes of organized convection between 02 and 12 Feb 2004. 


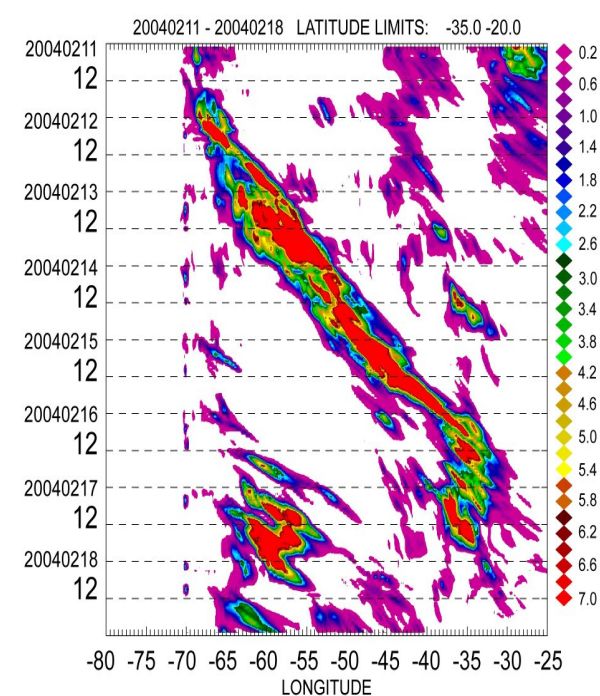

(a)

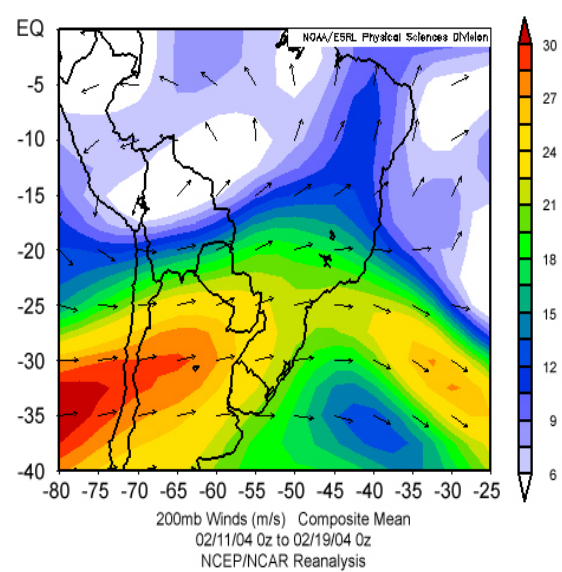

(c)

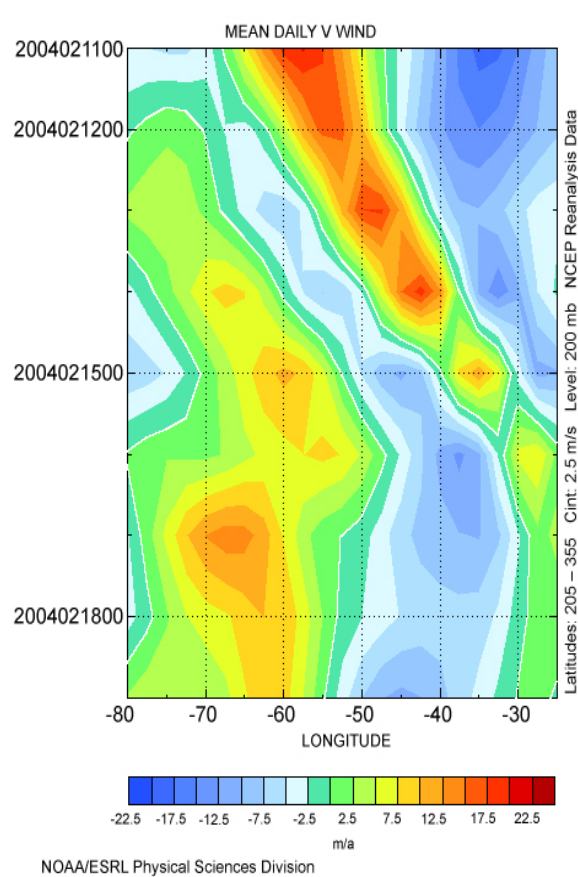

(b)

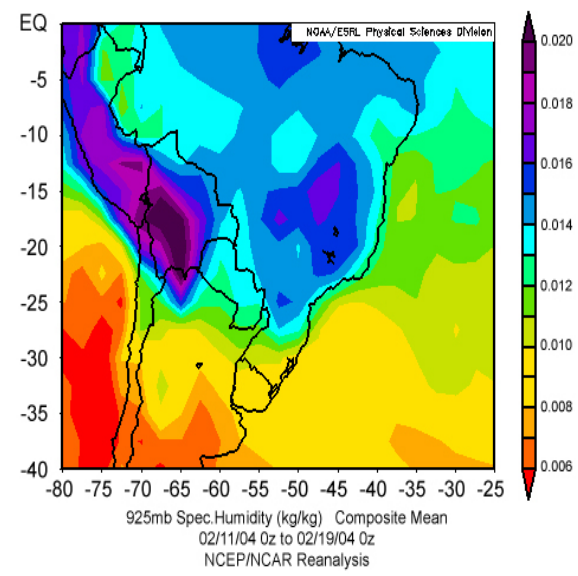

(d)

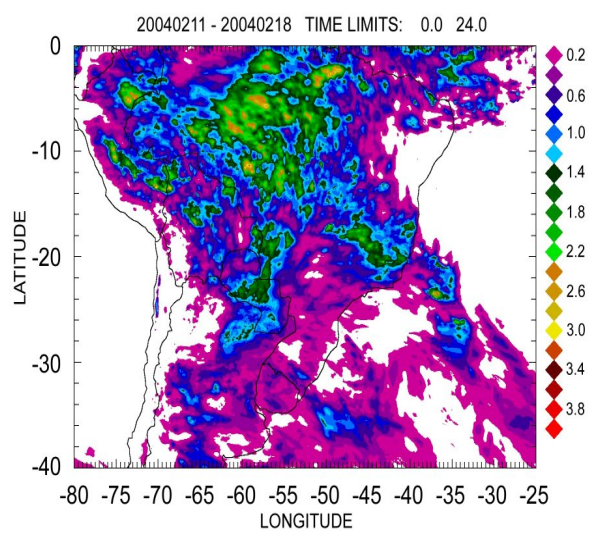

(e)

Figure 12. Similar to Figure 10 for episodes of organized convection between 02 and 12 Feb 2004. 


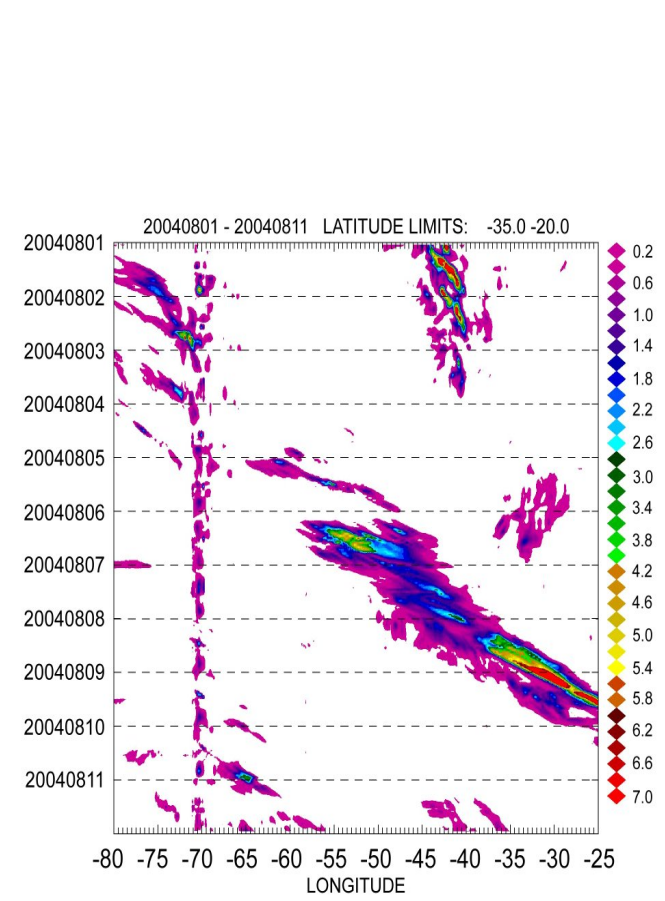

(a)

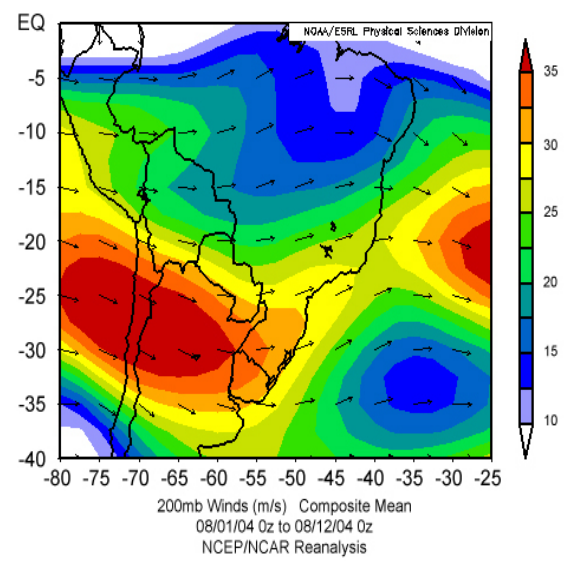

(c)

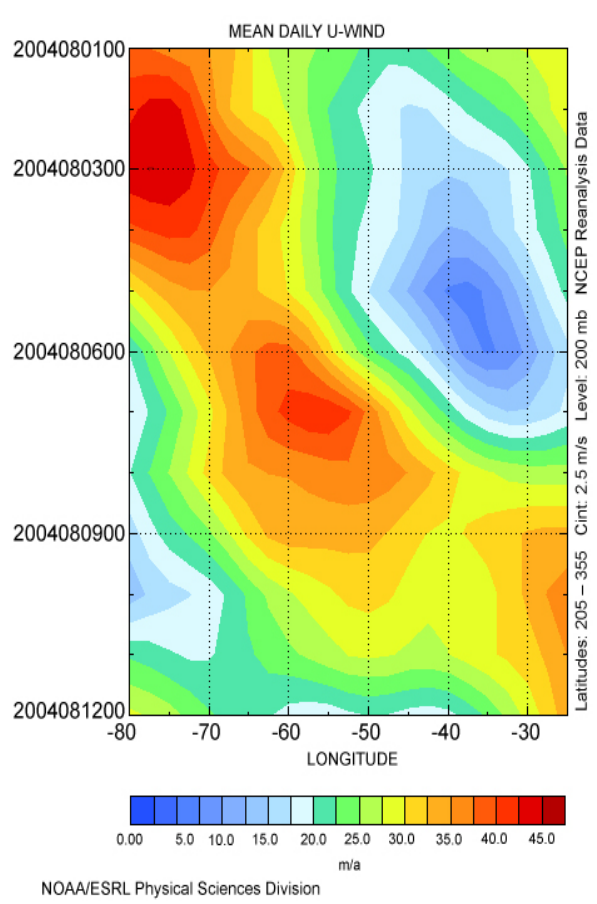

(b)

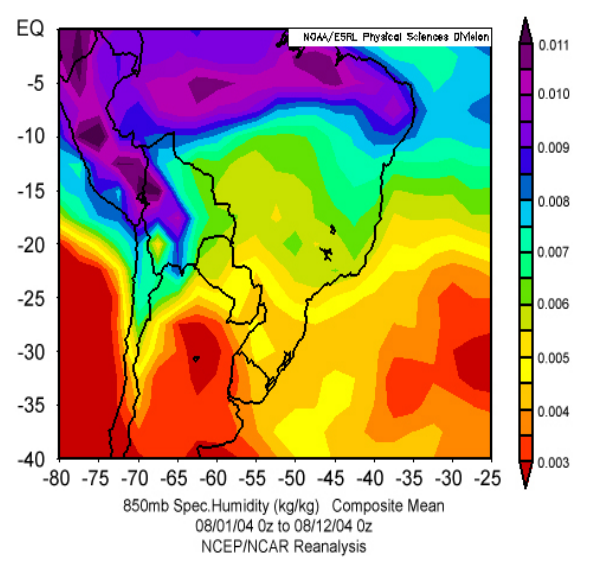

(d)

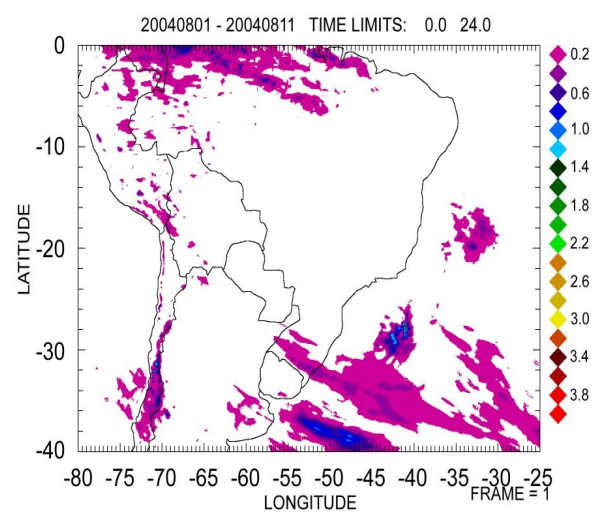

(e)

Figure 13. Similar to Figure 10 for episodes of organized convection between 11 and 19 Feb 2004. 


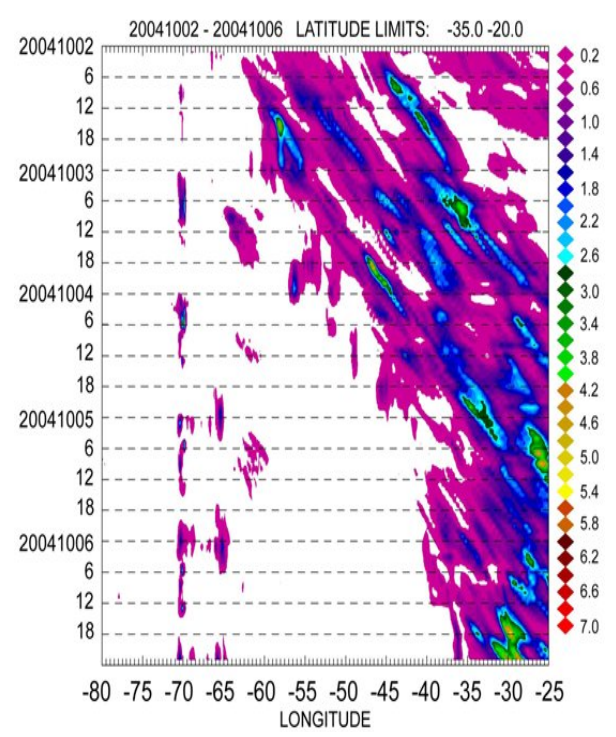

(a)

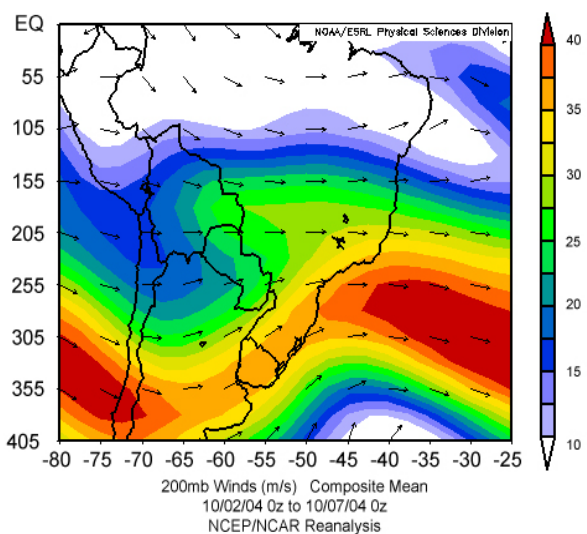

(c)

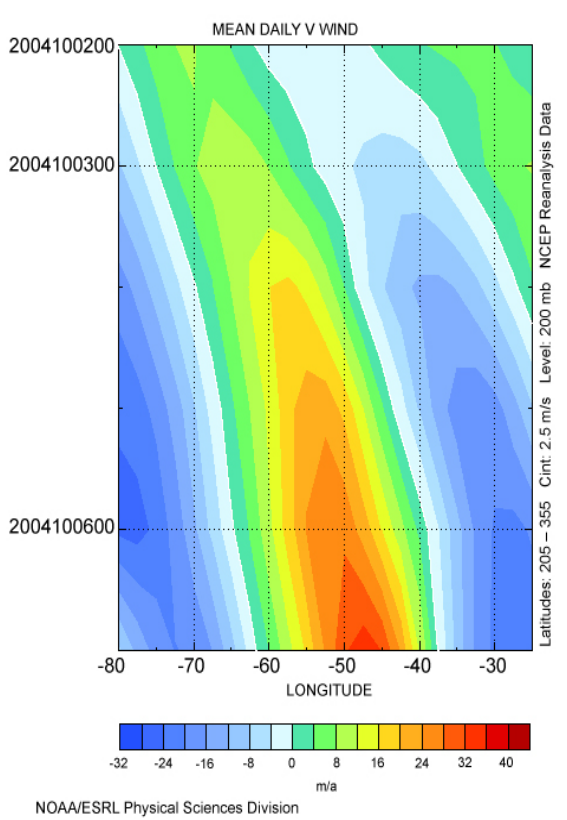

(b)

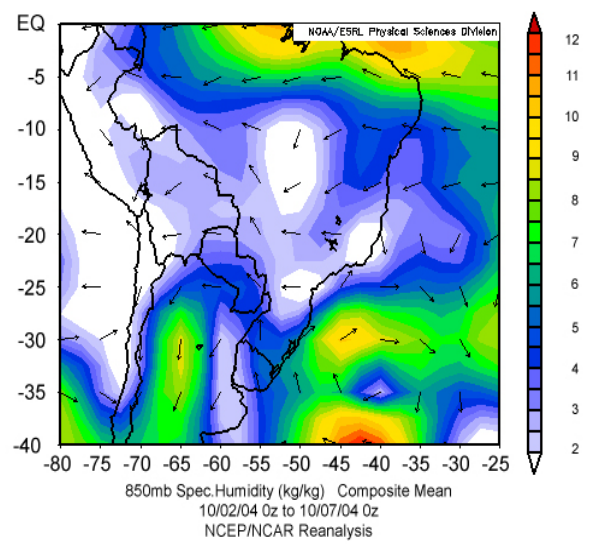

(d)

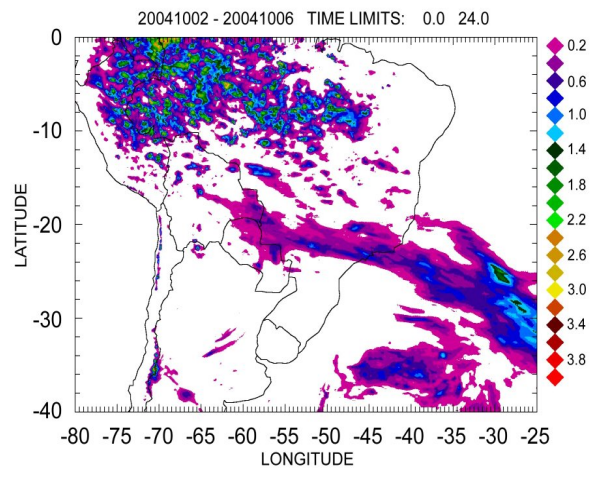

(e)

Figure 14. Episodes of organized convection between 23 and 29 November 2003. It shows Hovmöller diagrams of one-hour rainfall accumulation average (a) and 200-hPa zonal wind anomalies (b); the average 200-hPa wind field (c), average 850-hPa wind field (d) and the resulting rainfall accumulation (e). Longitudes, latitudes, geographic contours, colour scale are indicated. 


\section{Longest duration}
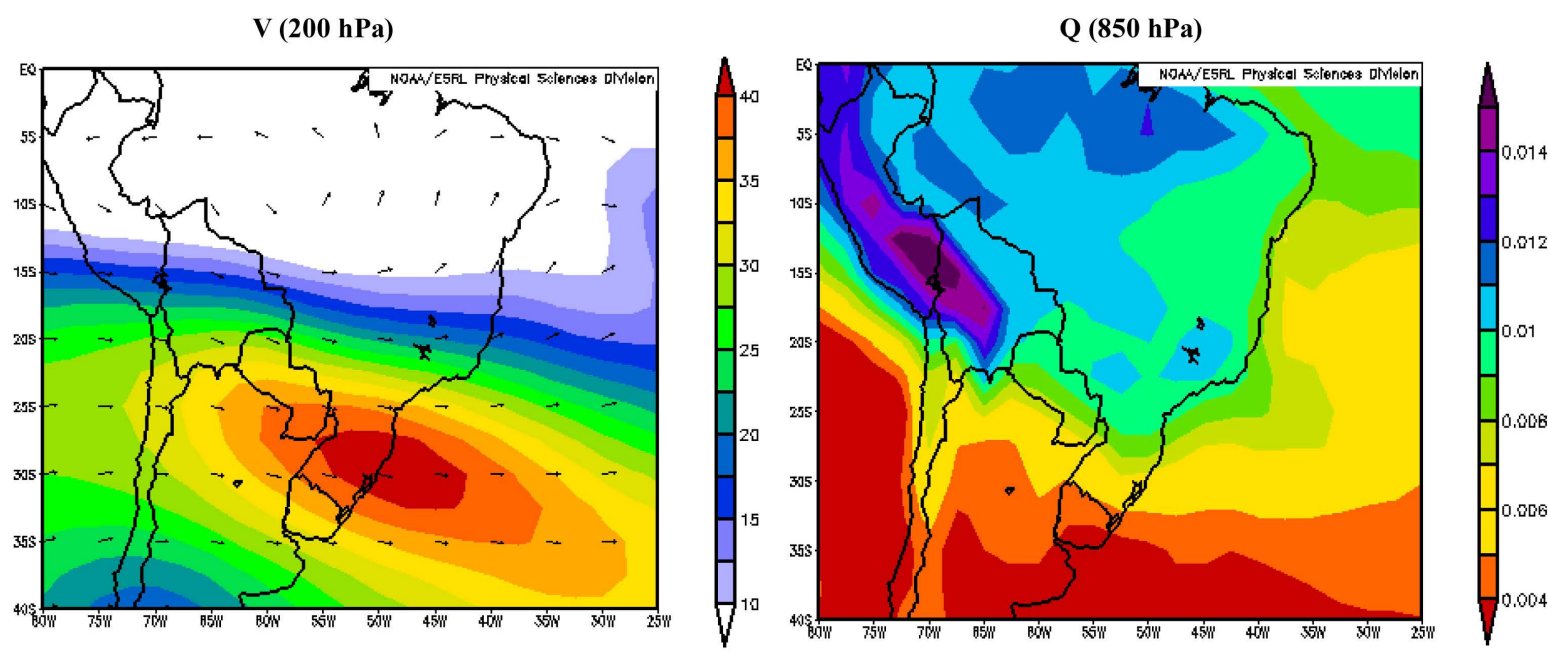

V (850 hPa)

\section{$\mathrm{T}(850 \mathrm{hPa})$}
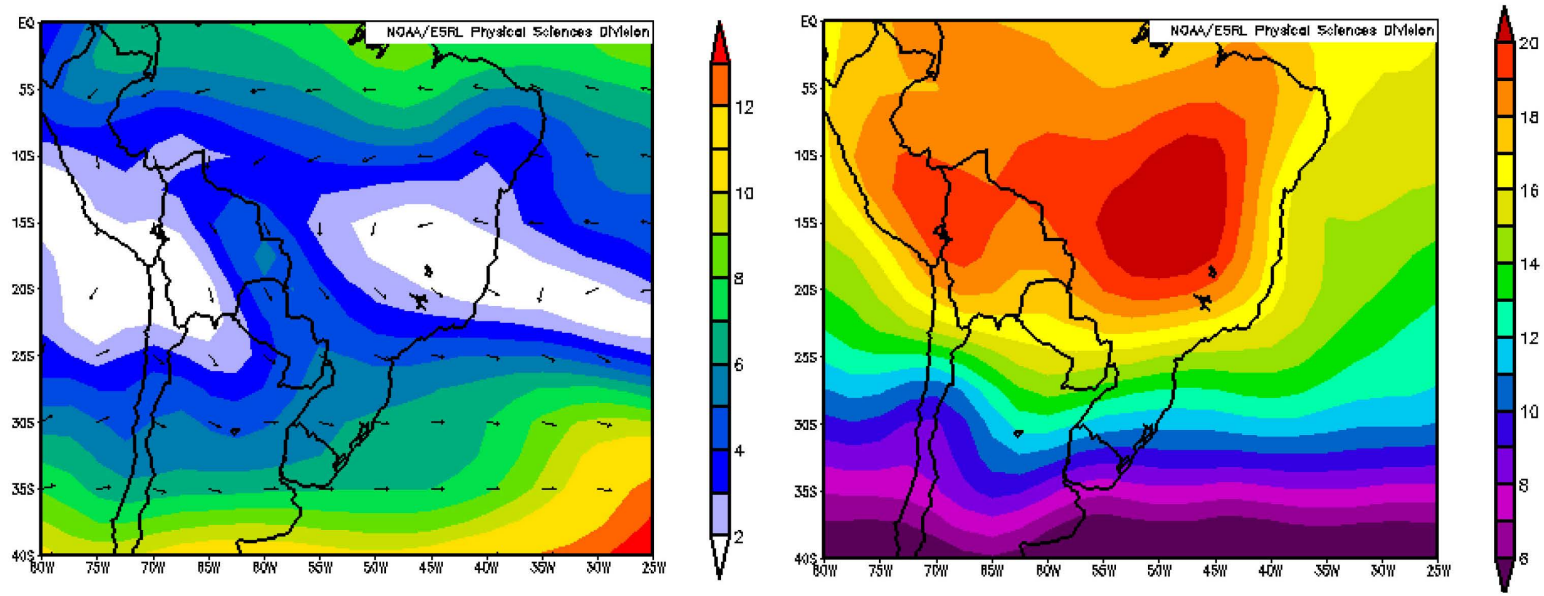

Figure 15. Composite mean fields of $200-\mathrm{hPa}$ and 850 -hPa winds $\left(\mathrm{m} \cdot \mathrm{s}^{-1}\right), 850-\mathrm{hPa}$ specific humidity $\left(\mathrm{kg} \cdot \mathrm{kg}^{-1}\right)$ and temperature $\left({ }^{\circ} \mathrm{C}\right)$ for the 10 longest span systems starting at the Andes Mountains.

humidity fields from September to November of 2003 to 2005 were obtained and shown in Figure 17. The mean phase speed of organized convection computed from the Hovmöller in Table 2 is $15 \mathrm{~m} \cdot \mathrm{s}^{-1}$ during spring. The vertical profile of zonal winds indicate that it corresponds to $400 \mathrm{hPa}$ in Figure 17(a) which is the overall steering level for organized convection.

The mean position of the upper jet ( $200 \mathrm{hPa}$ ) shown in Figure $17(\mathrm{~b})$ is at $-30^{\circ} \mathrm{S}$ and such that the transverse upward motion at equatorial entrance is between $-20^{\circ} \mathrm{S}$ and $-25^{\circ} \mathrm{S}$ and $-80^{\circ} \mathrm{W}$ and $-65^{\circ} \mathrm{W}$. On the other hand, meridional winds (Figure 17(c)) are from the North throughout the troposphere from $-70^{\circ}$ to $-50^{\circ} \mathrm{W}$ favorable to transport moist from the moist rich Amazon region. The vertical cross section of specific humidity between the Equator to $-40^{\circ} \mathrm{S}$ and up to $700 \mathrm{hPa}$ is shown in Figure 17(d). A deep layer of moisture more than $10 \mathrm{~g} \mathrm{~kg}^{-1}$ goes from the ground level at $-35^{\circ} \mathrm{S}$ to $750 \mathrm{hPa}$ at the Equator. The main jet at $850 \mathrm{hPa}$ (Figure 17(e)) is just to the east of the maximum in specific humidity (Figure 17(f)). These overall dynamic and thermodynamic conditions are consistent with the higher frequency of organized convection in the La Plata in spring. As the satellite rainfall climatology suggests, similar conditions are also found in April.

Table 1 and Table 2 summarize the main statistics of span, duration, phase speed and recurrence of organized convection annually and seasonally obtained with the Hovmöller diagrams between 2003 and 2007 for westward and eastward propagating systems. Westward propagating systems have shorter span, duration and phase speeds than the eastward ones and correspond to $16 \%$ of all organized convection in the La Plata region. These systems 
Shortest duration

V (200 hPa)

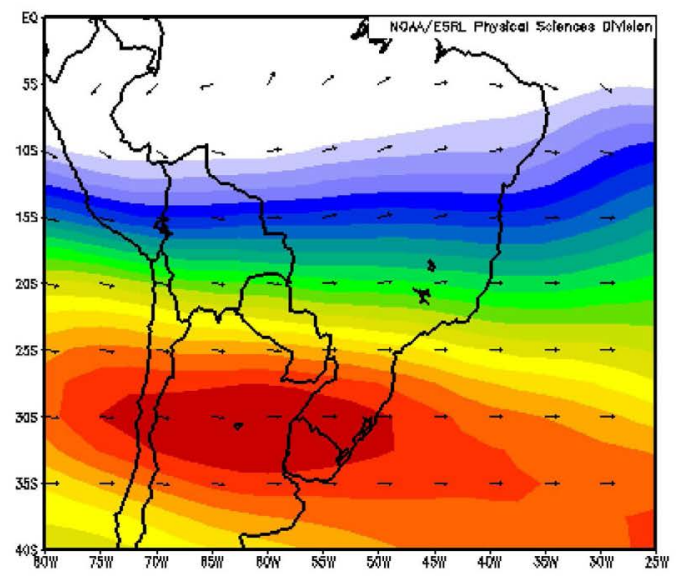

V (850 hPa)

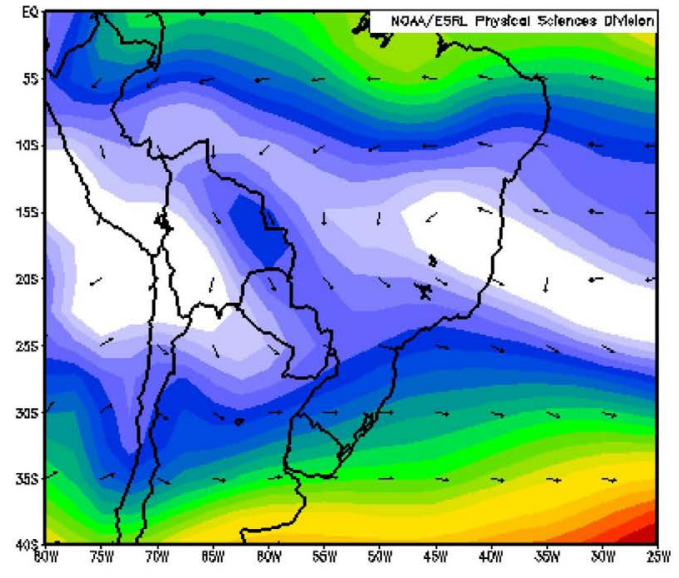

Q (850 hPa)
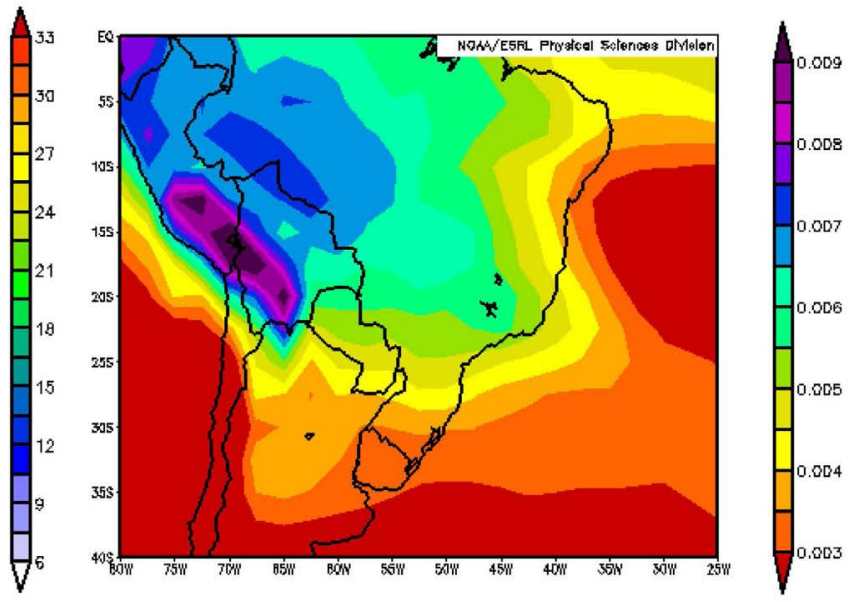

T (850 hPa)
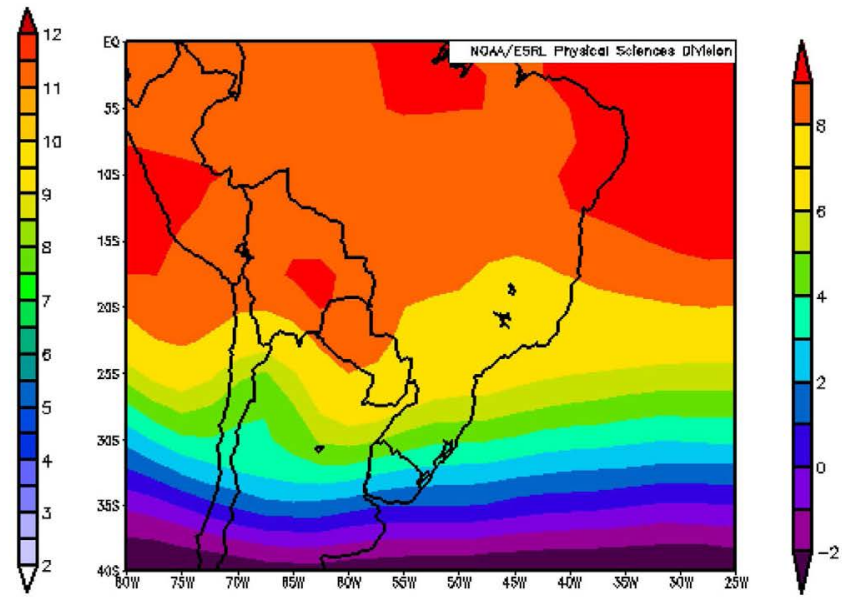

Figure 16. Similar to Figure 15 for 10 shortest span systems.

are related to direct circulations, sea breezes, in general. The more important eastward propagating system is responsible for higher rainfall accumulations. The longest spans (>2000 km) are of low frequency but are responsible for most of the rainfall accumulation. Figure 18 shows the average rainfall of system with spans 300 - 700 km, $701-1700 \mathrm{~km}$ and 1701 and $3700 \mathrm{~km}$ or a total of 210, 144 and 82 episodes, respectively. Longer system tends to have higher phase speeds and durations.

These "more important” systems hydrologically speaking tend to be more difficult to predict without adequate ground and upper level measurements and so forecast models are unable to reproduce the correct initial and contour conditions where spatial and temporal resolution of surface data, soundings and others are inadequate. But once convection is detected for instance by satellite IR and WV measurements at the Andes late in the evening under a upper level jet with enough vertical shear, it can be predicted its organization and longevity by the $400 \mathrm{hPa}$ zonal winds, the overall steering level of such long lasting precipitating systems.

\section{Summary and Conclusions}

Unique satellite-derived rainfall estimation with very high spatial and temporal resolution was used to study the main characteristics of organized convection over the La Plata Basins, an important watershed in South America. Episodes of organized convection have been analyzed by means of time-longitude fields of rainfall accumulation and a technique to compute the starting and ending longitudes and times of them, respective phase speeds, spans 


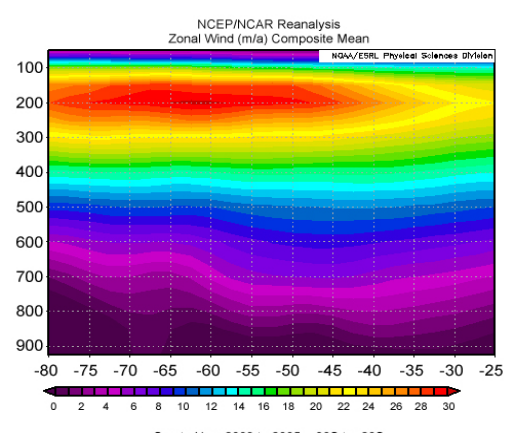

Sep to Nov: 2003 to 2005 -30S to -20S

(a)

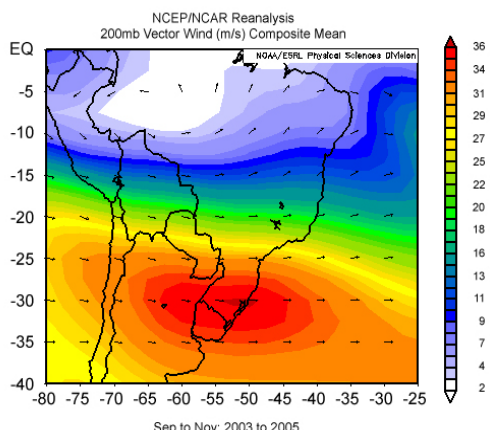

(d)

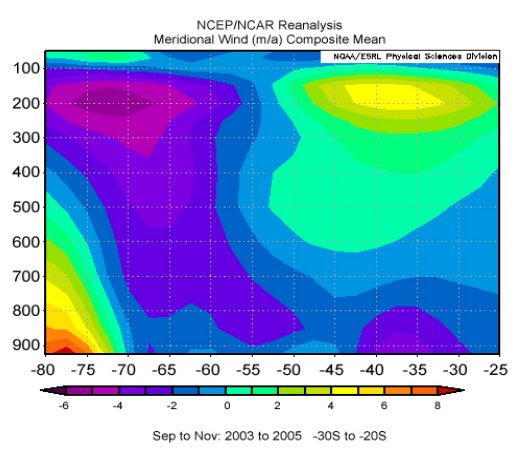

(b)

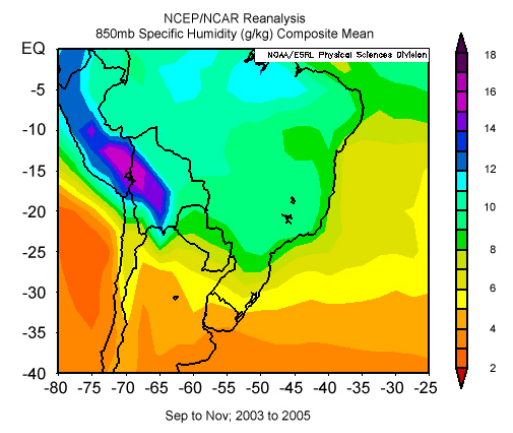

(e)

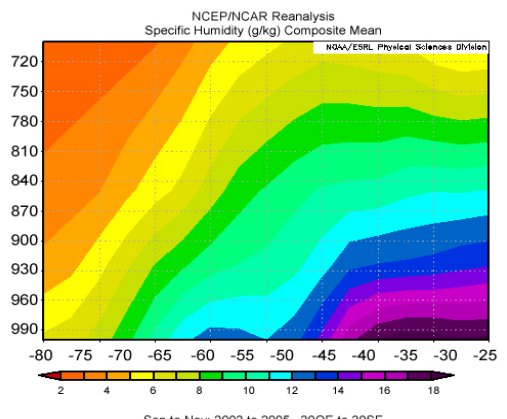

(c)

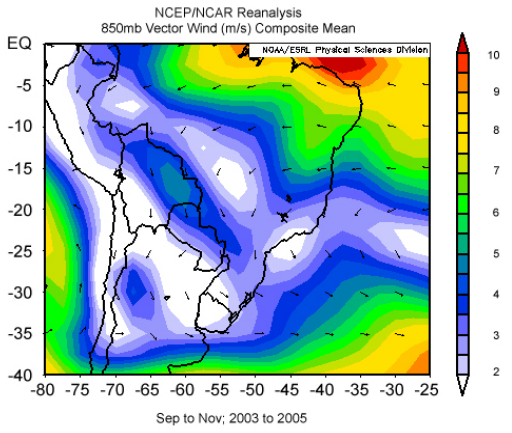

(f)

Figure 17. Composites of vertical cross sections of zonal (a) and meridional winds (b), specific humidity (c), 200-hPa wind (d) and 850-hPa specific humidity (e) and 850-hPa winds (f) and fields from September to November of 2003 to 2005. Longitudes, latitudes, geographic contours, color scale are indicated.

Table 1. Statistics of convective episodes in the La Plata basin $\left(-25 \mathrm{P}^{\circ} \mathrm{P}\right.$ W to $-80 \mathrm{P}^{\circ} \mathrm{P} \mathrm{W} ;-20 \mathrm{P}^{\circ} \mathrm{P}$ S to $\left.-40 \mathrm{P}^{\circ} \mathrm{P} S\right) \mathrm{Westward}^{-}$ moving rainfall episodes in La Plata Basin.

\begin{tabular}{|c|c|c|c|c|c|c|c|}
\hline \multicolumn{8}{|l|}{ WESTWARD } \\
\hline \multicolumn{8}{|l|}{ Annual (507) } \\
\hline Recurrence Frequency & 1/day & 2/day & 1/week & 1/2 week & 1/month & Mean & Median \\
\hline Span (km) & $\sim$ & $\sim$ & 222 & 340 & 433 & 280 & 266 \\
\hline Duration (h) & $\sim$ & $\sim$ & 5.0 & 8.0 & 12.0 & 7.2 & 6.0 \\
\hline Phase Speed $\left(\mathrm{m} \cdot \mathrm{s}^{-1}\right)$ & $\sim$ & $\sim$ & -11.3 & -15.5 & -19.5 & -12.3 & -11.5 \\
\hline \multicolumn{8}{|l|}{ DJF (172) } \\
\hline Recurrence Frequency & 1/day & 2/day & 1/week & $1 / 2$ week & $1 /$ month & Mean & Median \\
\hline Span (km) & $\sim$ & $\sim$ & 328 & 427 & 575 & 304 & 241 \\
\hline Duration (h) & $\sim$ & $\sim$ & 7.0 & 10.0 & 14.0 & 7.3 & 6.0 \\
\hline $\begin{array}{c}\text { Phase Speed }\left(\mathrm{m} \cdot \mathrm{s}^{-1}\right) \\
\text { MAM (139) }\end{array}$ & $\sim$ & $\sim$ & -14.6 & -17.8 & -20.6 & -12.7 & -12.5 \\
\hline Recurrence Frequency & 1/day & 2/day & 1/week & 1/2 week & $1 /$ month & Mean & Median \\
\hline Span $(\mathrm{km})$ & $\sim$ & $\sim$ & 241 & 353 & 445 & 285 & 229 \\
\hline Duration (h) & $\sim$ & $\sim$ & 5.0 & 8.0 & 12.0 & 7.4 & 5.0 \\
\hline $\begin{array}{c}\text { Phase Speed }\left(\mathrm{m} \cdot \mathrm{s}^{-1}\right) \\
\text { JJA (108) }\end{array}$ & $\sim$ & $\sim$ & -12 & -17.2 & -21.2 & -12.8 & -12 \\
\hline Recurrence Frequency & 1/day & 2/day & 1/week & 1/2 week & 1/month & Mean & Median \\
\hline Span (km) & $\sim$ & $\sim$ & 179 & 278 & 304 & 247 & 217 \\
\hline Duration (h) & $\sim$ & $\sim$ & 5.0 & 8.0 & 11.0 & 7.0 & 5.0 \\
\hline $\begin{array}{c}\text { Phase Speed }\left(\mathrm{m} \cdot \mathrm{s}^{-1}\right) \\
\text { SON }(88)\end{array}$ & $\sim$ & $\sim$ & -10 & -12.9 & -16.6 & -11.3 & -10.3 \\
\hline Recurrence Frequency & 1/day & 2/day & 1/week & 1/2 week & $1 /$ month & Mean & Median \\
\hline Span $(\mathrm{km})$ & $\sim$ & $\sim$ & 167 & 285 & 359 & 265 & 229 \\
\hline Duration (h) & $\sim$ & $\sim$ & 4.0 & 7.0 & 11.0 & 7.3 & 4.0 \\
\hline Phase Speed $\left(\mathrm{m} \cdot \mathrm{s}^{-1}\right)$ & $\sim$ & $\sim$ & -7.7 & -12.7 & -17.2 & -11.6 & -10.3 \\
\hline
\end{tabular}


Table 2. Similar to Table 1. except for Eastward moving rainfall episodes in La Plata Basin.

\begin{tabular}{|c|c|c|c|c|c|c|c|}
\hline \multicolumn{8}{|l|}{ EASTWARD } \\
\hline \multicolumn{8}{|l|}{ Annual (2607) } \\
\hline Recurrence Frequency & 1/day & 2/day & 1/week & 1/2 week & 1/month & Mean & Median \\
\hline Span (km) & 285 & 674 & 1719 & 2313 & 2752 & 713.2 & 451 \\
\hline Duration (h) & 5.0 & 13.0 & 31.0 & 45.0 & 57.0 & 13.8 & 9.0 \\
\hline Phase Speed $\left(\mathrm{m} \cdot \mathrm{s}^{-1}\right)$ & 11.7 & 17.2 & 23.7 & 26.3 & 28.3 & 15.4 & 14.8 \\
\hline \multicolumn{8}{|l|}{ DJF (698) } \\
\hline Recurrence Frequency & 1/day & 2/day & 1/week & $1 / 2$ week & $1 /$ month & Mean & Median \\
\hline Span (km) & 322 & 600 & 1403 & 1787 & 2232 & 610 & 433 \\
\hline Duration (h) & 6.0 & 11.0 & 25.0 & 33.0 & 47.0 & 11.4 & 8.0 \\
\hline $\begin{array}{c}\text { Phase Speed }\left(\mathrm{m} \cdot \mathrm{s}^{-1}\right) \\
\text { MAM (704) }\end{array}$ & 12.8 & 18.2 & 24.5 & 27.1 & 28.6 & 15.8 & 15.1 \\
\hline Recurrence Frequency & 1/day & 2/day & 1/week & $1 / 2$ week & $1 /$ month & Mean & Median \\
\hline Span (km) & 298 & 662 & 1577 & 2177 & 2721 & 662 & 408 \\
\hline Duration (h) & 6.0 & 13.0 & 30.0 & 50.0 & 59.0 & 13.4 & 8.0 \\
\hline $\begin{array}{c}\text { Phase Speed }\left(\mathrm{m} \cdot \mathrm{s}^{-1}\right) \\
\text { JJA }(578)\end{array}$ & 11.7 & 17.2 & 23.5 & 25.8 & 27.5 & 14.8 & 14.1 \\
\hline Recurrence Frequency & 1/day & 2/day & 1/week & 1/2 week & $1 /$ month & Mean & Median \\
\hline Span (km) & 216 & 705 & 2041 & 2478 & 2746 & 817 & 575 \\
\hline Duration (h) & 4.0 & 13.0 & 35.0 & 46.0 & 57.0 & 15.5 & 11.0 \\
\hline $\begin{array}{c}\text { Phase Speed }\left(\mathrm{m} \cdot \mathrm{s}^{-1}\right) \\
\text { SON }(627)\end{array}$ & 10.6 & 16.2 & 23.4 & 26.3 & 28.6 & 15.5 & 15.3 \\
\hline Recurrence Frequency & 1/day & 2/day & 1/week & 1/2 week & 1/month & Mean & Median \\
\hline Span (km) & 291 & 736 & 1756 & 2628 & 3080 & 790 & 513 \\
\hline Duration (h) & 5.0 & 14.0 & 36.0 & 52.0 & 61.0 & 15.2 & 9.0 \\
\hline Phase Speed $\left(\mathrm{m} \cdot \mathrm{s}^{-1}\right)$ & 11.7 & 17.3 & 23.6 & 26.2 & 28.3 & 15.6 & 15.1 \\
\hline
\end{tabular}

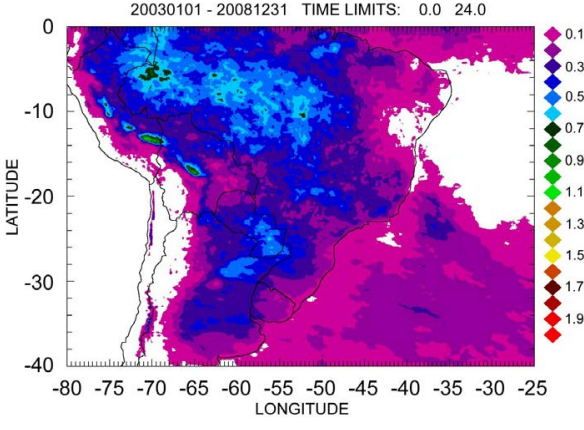

(a)

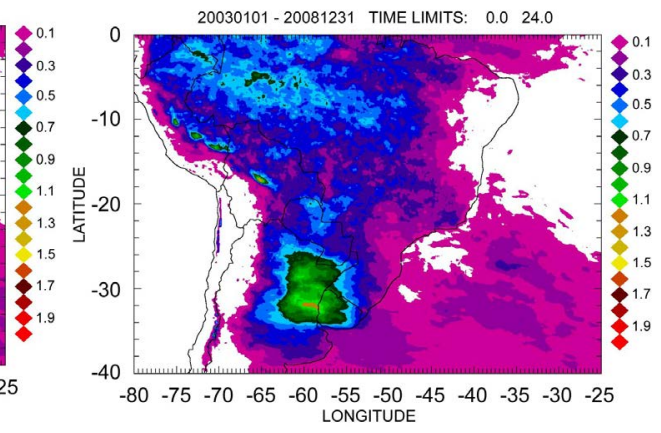

(b)

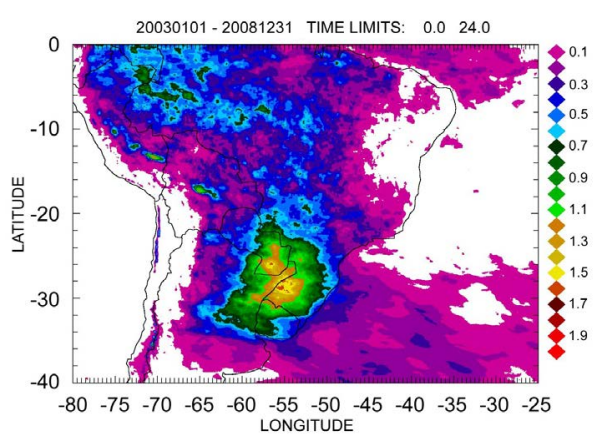

(c)

Figure 18. Average rainfall fields (mm) for all organized convection systems stating at Andes Mountain range between 2003 and 2008 with spans of $300 \mathrm{~km}$ to $700 \mathrm{~km}$ (a), $701 \mathrm{~km}$ to $1700 \mathrm{~km}$ (b) and $1701 \mathrm{~km}$ to $3700 \mathrm{~km}$ (c) corresponding to 210, 144 and 82 episodes, respectively. 
and duration. Basic statistics have been obtained for more 3000 episodes in the La Plata Basin. Spring episodes propagate eastward with average span, duration and phase speed of $565 \mathrm{~km}, 13 \mathrm{hr}$ and $13 \mathrm{~m} \cdot \mathrm{s}^{-1}$. Long span eastward episodes in the La Plata Systems start at Andes Cordillera, and have higher phase speeds and higher rainfall accumulation. In the La Plata transient systems such as cold fronts, front genesis and waves trigger by topography alter the diurnal cycle of convection. The CMORPH data set also allowed a quantitative evaluation of the intraseasonal and interannual variation of rainfall accumulation and interannual variability of diurnal cycle.

\section{Acknowledgements}

This research was sponsored by the National Council for Scientific and Technological Development (CNPq), under grant 304978/2011-6. The authors express their gratitude to their respective organizations for providing opportunities and means for this research. The authors are also thankful to CPC/NCEP for providing CMOPRH datasets. Special thanks to Mrs. Silvana H. Y. Silveira for formatting the Figures. The first author is specially grateful to the National Center for Atmospheric Research, Boulder, Colorado, for the logistic support received during the development of this research work.

\section{References}

[1] Velasco, I. and Fritsch, J.M. (1987) Mesoscale Convective Complexes in the Americas. Journal of Geophysical Research, 92, 9591-9613. http://dx.doi.org/10.1029/JD092iD08p09591

[2] Laing, A.G. and Fritsch, J.M. (1993) Mesoscale Convective Complexes over the Indian Monsoon Region. Journal of Climate, 6, 911-919. http://dx.doi.org/10.1175/1520-0442(1993)006<0911:MCCOTI $>2.0 . C O ; 2$

[3] Vera, C., Baez, J., Douglas, M., Emmanuel, C.B., Marengo, J., Meitin, J., Nicolini, M., Nogues-Paegle, J., Paegle, J., Penalba, O., Salio, P., Saulo, C., Silva Dias, M.A., Silva Dias, P. and Zipser, E. (2006) The South American LowLevel Jet Experiment (SALLJEX). Bulletin of the American Meteorological Society, 87, 63-77. http://dx.doi.org/10.1175/BAMS-87-1-63

[4] Joyce, R.J., Janowiak, J.E., Arkin, P.A. and Xie, P. (2004) CMORPH: A Method That Produces Global Precipitation Estimates from Passive Microwave and Infrared Data at High Spatial and Temporal Resolution. Journal of Hydrometeorology, 5, 487-503. http://dx.doi.org/10.1175/1525-7541(2004)005<0487:CAMTPG>2.0.CO;2

[5] Huffman, G.J., Adler, R.F., Bolvin, D.T., Gu, G., Nelkin, E.J., Bowman, K.P., Hong, Y., Stocker, E.F. and Wolff, D.B. (2007) The TRMM Multi-Satellite Precipitation Analysis: Quasi-Global, Multi-Year, Combined-Sensor Precipitation Estimates at Fine Scale. Journal of Hydrometeorology, 8, 38-55. http://dx.doi.org/10.1175/JHM560.1

[6] Hsu, K.-L., Gao, X., Sorooshian, S. and Gupta, V. (1997) Precipitation Estimation from Remotely Sensed Information Using Artificial Neural Networks. Journal of Applied Meteorology, 36, 1176-1190. http://dx.doi.org/10.1175/1520-0450(1997)036<1176:PEFRSI >2.0.CO;2 http://dx.doi.org/10.1175/2009JHM1139.1

[7] Ebert, E.E., Janowiak, J.E. and Kidd, C. (2007) Comparison of Near Real Time Precipitation Estimates from Satellite Observations and Numerical Models. Bulletin of the American Meteorological Society, 88, 47-64. http://dx.doi.org/10.1175/BAMS-88-1-47

[8] Pereira Filho, A.J., Carbone, R.E., Janowiak, J.E., Arkin, P., Joyce, R., Hallak, R. and Ramos, C.G.M. (2009) Satellite Rainfall Estimates over South America: Possible Applicability to the Water Management of Large Watersheds. Journal of the American Water Resources Association, 46, 344-360. http://dx.doi.org/10.1111/j.1752-1688.2009.00406.x

[9] Peixoto, J.P. and Oort, A.H. (1992) Physics of Climate. American Institute of Physics, College Park, 520 p.

[10] Carbone, R.E., Tuttle, J.D., Ahijevych, D.A. and Trier, D.S.B. (2002) Inferences of Predictability Associated with Warm Season Precipitation Episodes. Journal of the Atmospheric Sciences, 59, 2033-2056. http://dx.doi.org/10.1175/1520-0469(2002)059<2033:IOPAWW>2.0.CO;2

[11] Liu, C. and Zipser, E.J. (2008) Diurnal Cycles of Precipitation, Clouds and Lightning in the Tropics from 9 Years of TRMM Observations. Geophysical Research Letters, 35, Article ID: L04819. http://dx.doi.org/10.1029/2007GL032437

[12] Keenan, T.D. and Carbone, R.E. (2008) Propagation and Diurnal Evolution of Warm Season Cloudiness in the Australian and Maritime Continent Region. Monthly Weather Review, 136, 973-994. http://dx.doi.org/10.1175/2007MWR2152.1

[13] Laing, A.G., Carbone, R., Levizzani, V. and Tuttle, J. (2008) The Propagation and Diurnal Cycles of Deep Convection in Northern Tropical Africa. Quarterly Journal of the Royal Meteorological Society, 134, 93-109. http://dx.doi.org/10.1002/qi.194 
[14] Gan, M.A. and Rao, V.B. (1991) Surface Cyclogenesis over South America. Monthly Weather Review, 119, $1293-1302$. http://dx.doi.org/10.1175/1520-0493(1991)119<1293:SCOSA>2.0.CO;2

[15] Silva, G.A.M., Ambrizzi, T. and Marengo, J.A. (2009) Observational Evidences on the Modulation of the South American Low Level Jet East of the Andes According the ENSO Variability. Annales Geophysicae, 27, 645-657.

http://dx.doi.org/10.5194/angeo-27-645-2009 
Scientific Research Publishing (SCIRP) is one of the largest Open Access journal publishers. It is currently publishing more than 200 open access, online, peer-reviewed journals covering a wide range of academic disciplines. SCIRP serves the worldwide academic communities and contributes to the progress and application of science with its publication.

Other selected journals from SCIRP are listed as below. Submit your manuscript to us via either submit@scirp.org or Online Submission Portal.
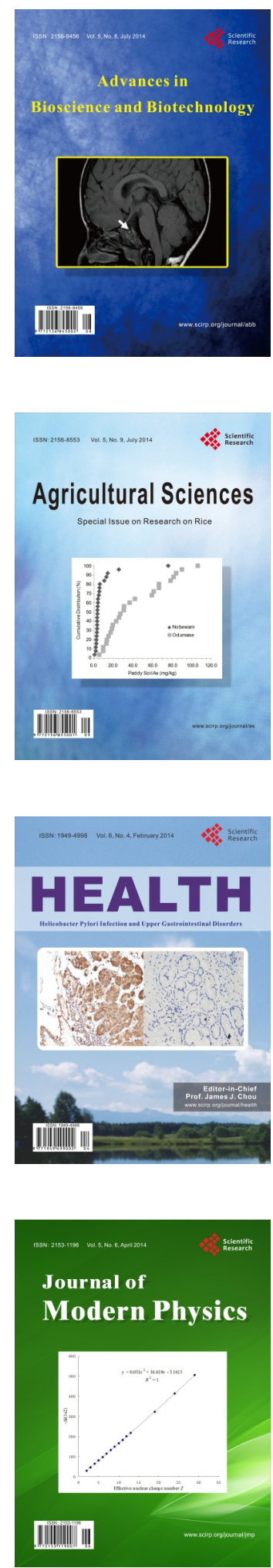
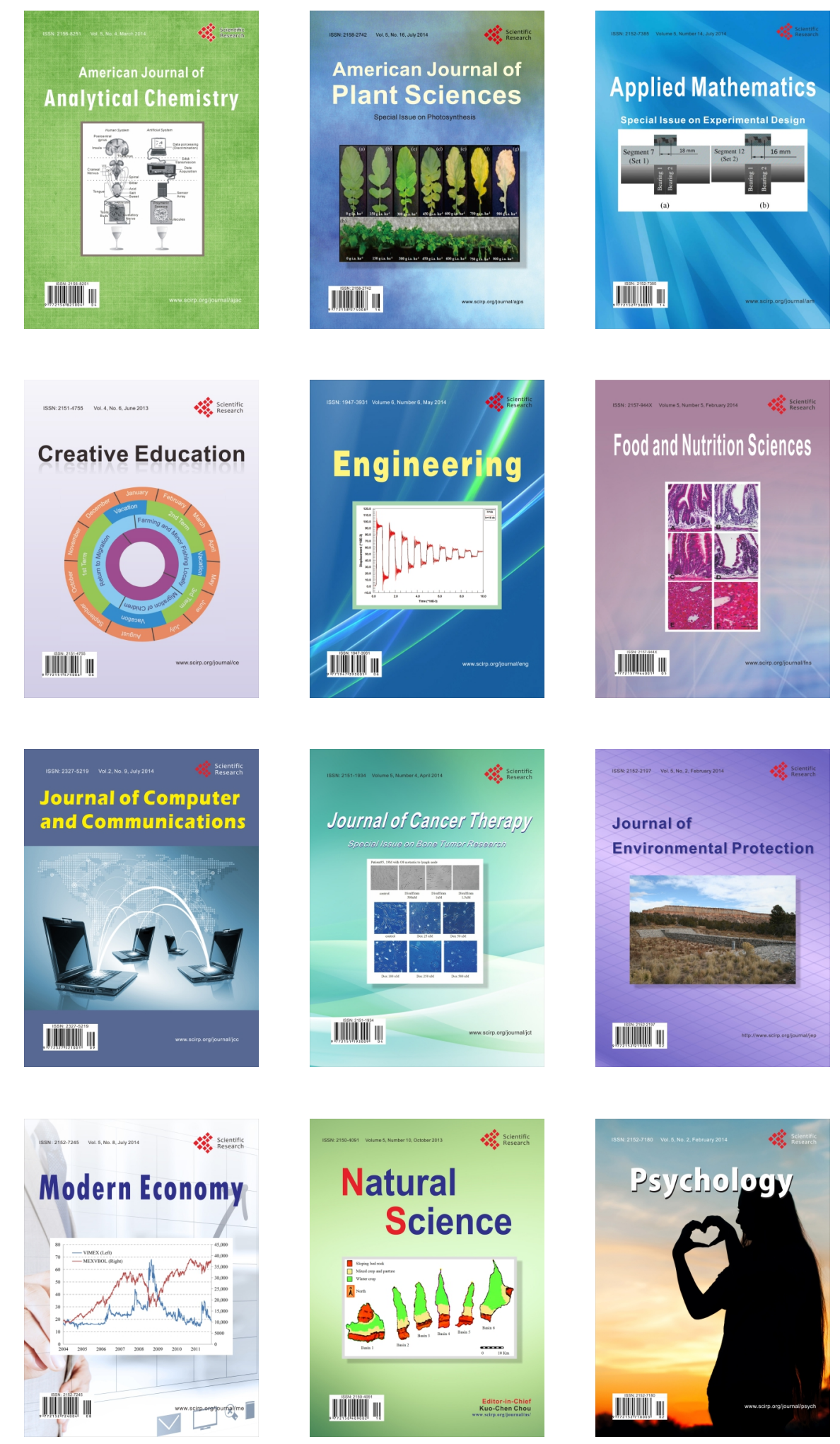